\title{
Atomic Layer Deposition of Emerging 2D Semiconductors, HfS2 and ZrS2, for Optoelectronics
}

\section{Mattinen, Miika}

2019-08-13

Mattinen , M , Popov , G, Vehkamäki , M , King , P J , Mizohata , K, Jalkanen , P , Räisänen , J , Leskelä , M \& Ritala , M 2019 , ' Atomic Layer Deposition of Emerging 2D

Semiconductors, HfS2 and ZrS2, for Optoelectronics ' , Chemistry of Materials, vol. 31 , no.

15 , pp. 5713-5724 . https://doi.org/10.1021/acs.chemmater.9b01688

http://hdl.handle.net/10138/305208

https://doi.org/10.1021/acs.chemmater.9b01688

cc_by

publishedVersion

Downloaded from Helda, University of Helsinki institutional repository.

This is an electronic reprint of the original article.

This reprint may differ from the original in pagination and typographic detail.

Please cite the original version. 


\title{
Atomic Layer Deposition of Emerging 2D Semiconductors, $\mathrm{HfS}_{2}$ and $\mathrm{ZrS}_{2}$, for Optoelectronics
}

\author{
Miika Mattinen, ${ }^{*}{ }^{\dagger}$ Georgi Popov, ${ }^{\dagger}$ Marko Vehkamäki, ${ }^{\dagger}$ Peter J. King, ${ }^{\dagger, \S}$ Kenichiro Mizohata, ${ }^{\ddagger}$ \\ Pasi Jalkanen, Jyrki Räisänen, ${ }^{\ddagger}$ Markku Leskelä, ${ }^{\dagger}$ and Mikko Ritala* ${ }^{*}+{ }^{\dagger}$ \\ ${ }^{\dagger}$ Department of Chemistry, and Division of Materials Physics, Department of Physics, University of Helsinki, P.O. Box 43, Helsinki \\ 00014, Finland
}

Supporting Information

ABSTRACT: Semiconducting two-dimensional (2D) materials are studied intensively because of their promising performance in diverse applications from electronics to energy storage and catalysis. Recently, $\mathrm{HfS}_{2}$ and $\mathrm{ZrS}_{2}$ have emerged as potential rivals for the commonly studied $2 \mathrm{D}$ semiconductors such as $\mathrm{MoS}_{2}$ and $\mathrm{WSe}_{2}$, but their use is hindered by the difficulty of producing continuous films. Herein, we report the first atomic layer deposition (ALD) processes for $\mathrm{HfS}_{2}$ and $\mathrm{ZrS}_{2}$ using $\mathrm{HfCl}_{4}$ and $\mathrm{ZrCl}_{4}$ with $\mathrm{H}_{2} \mathrm{~S}$ as the precursors. We demonstrate the deposition of uniform and continuous films on a range of substrates with accurately controlled thicknesses ranging from a few monolayers to tens
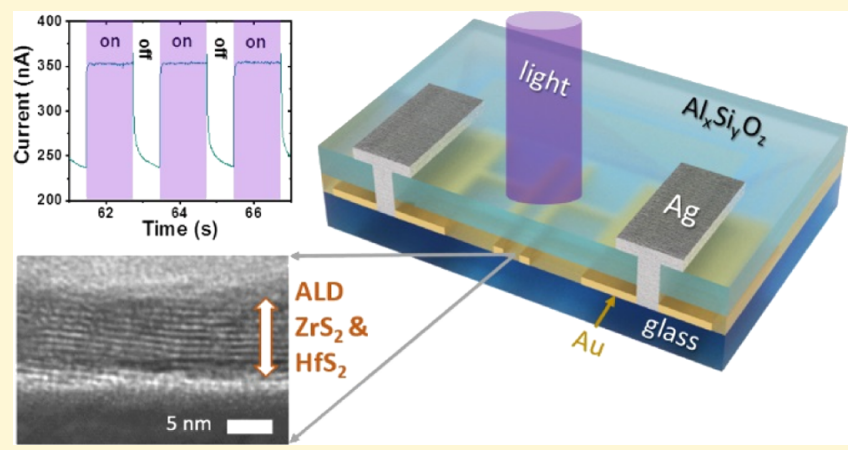
of nanometers. The use of semiconductor industry-compatible precursors and temperatures (approximately $400{ }^{\circ} \mathrm{C}$ ) enables facile upscaling of the process. The deposited $\mathrm{HfS}_{2}$ and $\mathrm{ZrS}_{2}$ films are crystalline, smooth, and stoichiometric with oxygen as the main impurity. As an important step toward applications of $\mathrm{HfS}_{2}$ and $\mathrm{ZrS}_{2}$, we show that their sensitivity toward oxidation can be overcome by minimizing the impurities in the reactor and by depositing a protective $\mathrm{Al}_{x} \mathrm{Si}_{y} \mathrm{O}_{z}$ layer on the top without a vacuum break. Finally, we demonstrate $\mathrm{HfS}_{2}$ and $\mathrm{ZrS}_{2}$ photodetectors exhibiting good performance and stable operation in ambient conditions. Photoresponsivity comparable to thin films or even single flakes of $\mathrm{HfS}_{2}$ or $\mathrm{ZrS}_{2}$ deposited at much higher temperatures is achieved, although the response speed seems to be limited by photogating, as is common for $2 \mathrm{D}$ photodetectors. We expect the first ALD processes for $\mathrm{HfS}_{2}$ and $\mathrm{ZrS} \mathrm{S}_{2}$ to enable further exploration of these materials for various semiconductor applications.

\section{INTRODUCTION}

Transition-metal dichalcogenides (TMDCs) form a large group of two-dimensional (2D) materials with different properties and a wide range of potential applications. The interest in TMDCs has rapidly increased in the wake of the prototypical $2 \mathrm{D}$ material graphene, a semimetallic single-atom thick layer of carbon. ${ }^{1,2}$ In particular, semiconducting sulfides and selenides of group 6 elements, molybdenum and tungsten, have been widely studied for various applications. ${ }^{3}$ On the other hand, semiconducting group 4 TMDCs, $\mathrm{ZrS}_{2}, \mathrm{ZrSe}_{2}$, $\mathrm{HfS}_{2}$, and $\mathrm{HfSe}_{2}$, have only very recently emerged as potential candidates for semiconductor applications (the electronic nature of $\mathrm{TiS}_{2}$ remains debated, whereas the other group 4 TMDCs are semimetals). ${ }^{4}$ Although there are very few studies on the properties of monolayer-thick group 4 TMDCs, it seems likely that both $\mathrm{HfS}_{2}$ and $\mathrm{ZrS}_{2}$ are indirect band gap semiconductors at all thicknesses. ${ }^{4,5}$ Their reported band gaps of 1.7-1.8 $\left(\mathrm{ZrS}_{2}\right)$ and $1.8-2.1 \mathrm{eV}\left(\mathrm{HfS}_{2}\right)$ in bulk are compatible with many semiconductor applications (see refs ${ }^{5,6}$ and references therein).

Experimental studies have shown that $\mathrm{HfS}_{2}$ and $\mathrm{ZrS}_{2}$ can match the performance of $\mathrm{MoS}_{2}$, a benchmark TMDC, in important (opto)electronic devices such as photodetectors ${ }^{7-10}$ and field-effect transistors. ${ }^{7-12}$ Theoretical calculations have predicted that the semiconducting group 4 TMDCs may exhibit even higher charge carrier mobilities than the group 6 TMDCs, ${ }^{13}$ but these predictions remain to be confirmed experimentally. ${ }^{5}$ Theoretical studies suggest both monolayer $\mathrm{HfS}_{2}{ }^{14}$ and $\mathrm{ZrS}_{2}{ }^{15}$ to be efficient water-splitting catalysts, although, so far, only bulk $\mathrm{HfS}_{2}$ and $\mathrm{ZrS}_{2}$ have been examined experimentally. ${ }^{16}$ Ultra-thin $\mathrm{ZrS}_{2}$ has also been studied for use in photocatalysis ${ }^{17}$ and lithium-ion batteries. ${ }^{18}$ Many of the applications explored for other TMDCs such as catalysis, solar cells, gas sensors, supercapacitors, and batteries remain to be explored for $\mathrm{HfS}_{2}$ and $\mathrm{ZrS}_{2}$.

In order to produce devices based on $\mathrm{HfS}_{2}$ and $\mathrm{ZrS}_{2}$ on a large scale, they must be deposited over large substrate areas in a cost-effective manner and with a good control over uniformity and thickness. Additionally, in many cases, continuous films are required, and low-deposition temper-

Received: April 29, 2019

Revised: July 2, 2019

Published: August 2, 2019 
atures are preferred. Besides micromechanical exfoliation of bulk crystals, chemical vapor deposition (CVD) has been demonstrated to be able to produce ultrathin $\mathrm{HfS}_{2}$ and $\mathrm{ZrS}_{2}$ flakes or films. CVD using $\mathrm{MCl}_{4}(\mathrm{M}=\mathrm{Hf}, \mathrm{Zr})$ and $\mathrm{S}$ powder as precursors has been reported, although at high temperatures of 900-1000 ${ }^{\circ} \mathrm{C}$ for $\mathrm{HfS}_{2}{ }^{7,19-22}$ and $600-900{ }^{\circ} \mathrm{C}$ for $\mathrm{ZrS}_{2}{ }^{10,11,23}$ Furthermore, continuous $\mathrm{HfS}_{2}$ (ref 21) and $\mathrm{ZrS}_{2}$ (ref 23) films are rarely achieved, and deposition on large, wafer-scale substrates has not yet been demonstrated.

We sought to prepare $\mathrm{HfS}_{2}$ and $\mathrm{ZrS}_{2}$ thin films using atomic layer deposition (ALD), which is a modification of the CVD method. In ALD, the precursors, typically one for each element present in the film, are supplied onto the substrate in individual, isolated pulses so that gas phase reactions are eliminated. Therefore, ALD film growth occurs only via selflimiting surface reactions, which enables ALD to uniformly coat both large areas and complex 3D shapes with a film of easily, accurately, and reproducibly controlled thickness. ${ }^{24-26}$ Advantageously, ALD processes are usually performed at relatively low temperatures below $500{ }^{\circ} \mathrm{C}$, and ALD can be scaled up for use in semiconductors and other industries. ${ }^{27,28}$

ALD has proven itself as a capable technique in synthesizing various TMDCs - the reader is referred to recent reviews for more details. ${ }^{31,32}$ The majority of ALD studies have concentrated on $\mathrm{MoS}_{2}$ with a lower number of reports on $\mathrm{SnS}_{2}$ and $\mathrm{WS}_{2}$. Although also $\mathrm{MoSe}_{2}, \mathrm{ReS}_{2}, \mathrm{TiS}_{2}$, and $\mathrm{WSe}_{2}$ have been deposited, many interesting TMDCs are still awaiting for ALD processes. Being a chemical method, the success of ALD relies on finding precursors that fulfill a set of requirements including thermal stability, adequate volatility, and high reactivity. ${ }^{24,27}$ Although a large number of ALD precursors have been used to deposit $\mathrm{HfO}_{2}$ and $\mathrm{ZrO}_{2}$ films, ${ }^{29,30}$ there have been, to the best of our knowledge, no reported attempts to prepare $\mathrm{HfS}_{2}$ or $\mathrm{ZrS}_{2}$ films by ALD.

$\mathrm{HfS}_{2}$ and $\mathrm{ZrS}_{2}$ films and crystals are known to oxidize under ambient conditions. ${ }^{33-35}$ Various approaches have been reported to increase their stability by encapsulation, including transferring a flake of a $2 \mathrm{D}$ material (h-BN) on the top ${ }^{34}$ or depositing a polymer ${ }^{36}$ or an ALD oxide film. ${ }^{8,37}$ Although these approaches have been shown to protect the films from the ambient, they still have some drawbacks. For example, the deposition of the protective film is done in a separate step using additional equipment, which increases the process complexity, time, and cost. The polymer films or h-BN flakes may be difficult to adopt in use in actual semiconductor devices. The ALD oxide films, used to protect $\mathrm{HfS}_{2} / \mathrm{ZrS}_{2}$, have so far been deposited using an oxidant such as water or ozone as the reactant, which may damage the sensitive $\mathrm{HfS}_{2}$ and $\mathrm{ZrS}_{2}$ films. In order to overcome these drawbacks, new encapsulation methods are needed.

In this work, we deposit continuous $\mathrm{HfS}_{2}$ and $\mathrm{ZrS}_{2}$ films from a few monolayers to tens of nanometers in thickness. Using simple halide precursors $\mathrm{HfCl}_{4}$ and $\mathrm{ZrCl}_{4}$ together with $\mathrm{H}_{2} \mathrm{~S}$, crystalline films are deposited at relatively low temperatures of approximately $400{ }^{\circ} \mathrm{C}$. The films grow well on oxideterminated silicon substrates as well as on different oxide, sulfide, and metal surfaces. We show that the sensitivity of $\mathrm{HfS}_{2}$ and $\mathrm{ZrS}_{2}$ toward oxidation needs to be taken into account during deposition, storage, and applications. To this end, we demonstrate a quick and simple way to encapsulate the $\mathrm{HfS}_{2}$ / $\mathrm{ZrS}_{2}$ films without a vacuum break. Finally, $\mathrm{HfS}_{2}$ and $\mathrm{ZrS}_{2}$ photodetectors are constructed to show the applicability and optoelectronic properties of our films.

\section{EXPERIMENTAL SECTION}

$\mathrm{HfS}_{2}$ and $\mathrm{ZrS}_{2}$ thin films were deposited by ALD using a commercial, hot-wall, cross-flow-type ALD reactor (F120, ASM Microchemistry). ${ }^{38}$ Nitrogen $\left(\mathrm{N}_{2}\right.$, AGA, $99.999 \%$, further purified as described below) served as both carrier and purge gas at a flow rate of $400 \mathrm{sccm}$, resulting in an operating pressure of approximately $5 \mathrm{mbar}$.

$\mathrm{HfCl}_{4}$ (Strem, 99.99\%) and $\mathrm{ZrCl}_{4}$ (Epivalence) were heated to 125-130 and $130-135{ }^{\circ} \mathrm{C}$, respectively, in open glass boats held inside the reactor and pulsed by inert gas valving. The reactor design and inert gas valving are described in refs. ${ }^{24,38}$ In order to minimize the air exposure, the air- and moisture-sensitive precursors were handled in a glove box under $\mathrm{N}_{2}$ before they were transferred into the ALD reactor. Hydrogen sulfide $\left(\mathrm{H}_{2} \mathrm{~S}\right.$, Linde, $99.5 \%$, further purified as described below) was pulsed using an external solenoid valve. The $\mathrm{H}_{2} \mathrm{~S}$ flow rate was set to $14 \mathrm{sccm}$ (under continuous flow) using a needle valve. Unless otherwise noted, the films were deposited at 400 ${ }^{\circ} \mathrm{C}$ using $1 \mathrm{~s}$ pulses and purges. Additional deposition experiments described in the Supporting Information (Section S2) were performed using $\mathrm{Hfl}_{4}, \mathrm{Hf}(\mathrm{NEtMe})_{4}$, and $\mathrm{Zr}(\mathrm{NEtMe})_{4}$ as metal precursors.

Thermodynamic calculations on film deposition and oxidation reactions were performed with the Outokumpu HSC Chemistry for Windows software (version 5.11).

As detailed in the Supporting Information (Section S1), we found the deposition processes to be very sensitive to impurities in the ALD reactor. Therefore, gas purifiers were installed for both $\mathrm{N}_{2}$ (SAES Microtorr MC1-902F, specified to remove $\mathrm{H}_{2} \mathrm{O}, \mathrm{H}_{2}, \mathrm{CO}_{2}, \mathrm{CO}$, and $\mathrm{O}_{2}$ to $<100 \mathrm{ppt}$, organic acids and refractory compounds to $<1 \mathrm{ppt}$, bases to $<5 \mathrm{ppt}$, and metals to $<1 \mathrm{ppb}$ ) and $\mathrm{H}_{2} \mathrm{~S}$ (SAES Microtorr MC1-302F, specified to remove $\mathrm{H}_{2} \mathrm{O}$ and metals to $<1 \mathrm{ppb}$ ).

As our ALD reactor is partially exposed to the atmosphere between film depositions, preconditioning of the reactor either by heating to $500{ }^{\circ} \mathrm{C}$ for $1 \mathrm{~h}$ or by preevacuation of the reactor tube was included in some cases. Using a different kind of an ALD reactor, especially one with a load lock, could eliminate the need of preconditioning, but the aforementioned gas purifiers would still be necessary. Both preannealing and preevacuation were found to markedly improve the uniformity of the $\mathrm{ZrS}_{2}$ films, whereas preconditioning had a smaller effect on the $\mathrm{HfS}_{2}$ films. In most cases, preannealing was used for $\mathrm{ZrS}_{2}$ depositions, whereas no preconditioning was usually used for $\mathrm{HfS}_{2}$ depositions. The preevacuation was used for the deposition of photodetector samples of both of the materials. The preconditioning procedures were observed to somewhat decrease the growth rates of the two materials, which is likely due to prevention of reactions between $\mathrm{MCl}_{4}$ and residual $\mathrm{H}_{2} \mathrm{O}$. The effect of preconditioning is believed to be mainly due to the removal of $\mathrm{H}_{2} \mathrm{O}$ from the walls of the colder parts of the reactor. More details on the preconditioning procedures are presented in the Supporting Information (Section S1).

The deposited $\mathrm{HfS}_{2}$ and $\mathrm{ZrS}_{2}$ films were found to oxidize in ambient conditions as has been reported previously. ${ }^{33-35}$ Therefore, a protective $50 \mathrm{~nm}$ thick $\mathrm{Al}_{x} \mathrm{Si}_{y} \mathrm{O}_{z}$ layer was deposited on the top of some of the $\mathrm{HfS}_{2} / \mathrm{ZrS}_{2}$ films immediately after deposition without a vacuum break. The protective layer was deposited at $400{ }^{\circ} \mathrm{C}$ using an oxidant-free ALD process with $\mathrm{AlCl}_{3}$ and $\mathrm{Si}\left(\mathrm{O}^{n} \mathrm{Bu}\right)_{4}$ as the precursors. ${ }^{39}$ In contrast, a conventional $\mathrm{H}_{2} \mathrm{O}$-based ALD process using $\mathrm{AlCl}_{3}$ and $\mathrm{H}_{2} \mathrm{O}$ at $400{ }^{\circ} \mathrm{C}$ was found to partially oxidize the films. The oxidizing effect of water was confirmed by pulsing only $\mathrm{H}_{2} \mathrm{O}$ over the $\mathrm{HfS}_{2} / \mathrm{ZrS}_{2}$ films at $400{ }^{\circ} \mathrm{C}$ (Figure S23).

The $\mathrm{HfS}_{2}$ and $\mathrm{ZrS}_{2}$ films were mostly deposited on $5 \times 5 \mathrm{~cm}^{2}$ soda lime glass (SLG) and silicon substrates. The SLG substrates were cleaned in successive ultrasonic baths of alkaline ultrasonic detergent solution, tap water, ethanol, and de-ionized water, followed by careful rinsing using a 50:50 (v/v \%) solution of ethanol and deionized water and drying by pressurized air. The silicon substrates were blown clean of particles using a $\mathrm{N}_{2}$ stream. The native silicon oxide was not removed. Additionally, thermal $\mathrm{SiO}_{2}(90 \mathrm{~nm}) / \mathrm{Si}$, sapphire (2" wafers, $c$-plane off to $M$-plane by $0.2 \pm 0.1^{\circ}$, double-side polished, University Wafer), and muscovite mica ( $15 \mathrm{~mm}$ disks, V1 grade, Nano-Tec) as well as ALD-grown $\mathrm{Al}_{2} \mathrm{O}_{3}, \mathrm{Ir}, \mathrm{TiO}_{2}$, and $\mathrm{ZnS}$ films on silicon were used as substrates in some depositions. The sapphire wafers were 
(a)

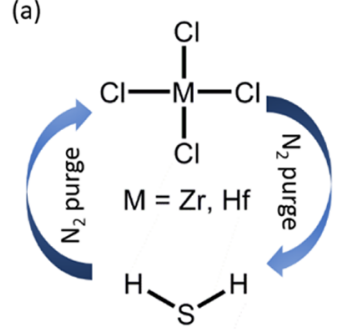

(b)

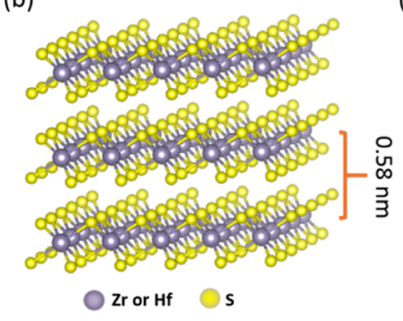

(c)

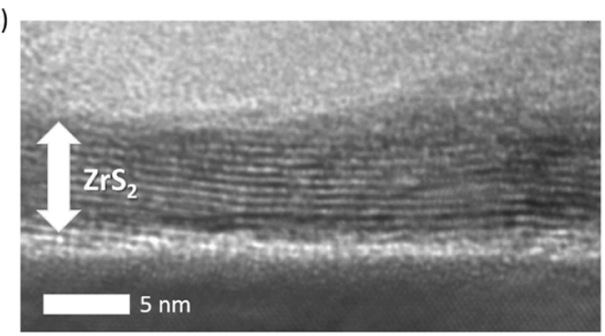

(d)

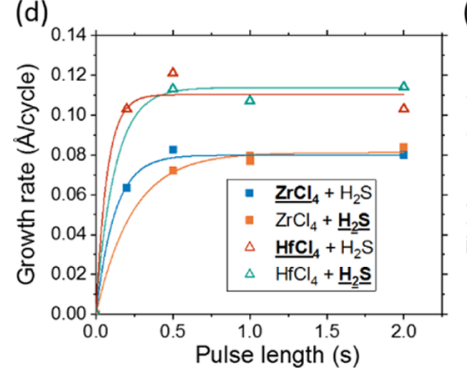

(e)

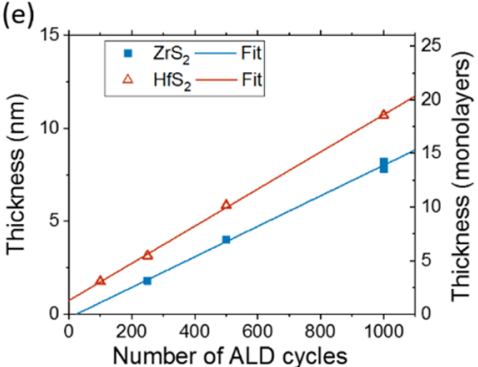

(f)

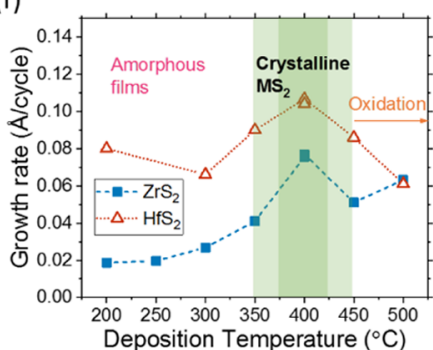

Figure 1. (a) Schematic of the ALD process used to deposit $\mathrm{HfS}_{2}$ and $\mathrm{ZrS}_{2}$ films. (b) Crystal structure of $1 \mathrm{~T} \mathrm{HfS}_{2}$ and $\mathrm{ZrS}_{2}$. (c) Cross-sectional TEM micrograph showing the layered structure of a $7 \mathrm{~nm} \mathrm{ZrS} \mathrm{Z}_{2}$ film as alternating light and dark layers. (d) Growth rates of $\mathrm{HfS}_{2}$ and $\mathrm{ZrS}_{2}$ at 400 ${ }^{\circ} \mathrm{C}$ as a function of precursor pulse lengths (the underlined pulse was varied). (e) Thickness of $\mathrm{HfS}_{2}$ and $\mathrm{ZrS}_{2}$ films vs the number of ALD cycles. (f) Growth rates of $\mathrm{HfS}_{2}$ and $\mathrm{ZrS}_{2}$ films as a function of deposition temperature. Green shading indicates the optimal temperatures. Unless otherwise noted, the films were deposited at $400{ }^{\circ} \mathrm{C}$ using 1000 cycles with $1 \mathrm{~s}$ pulses and purges. The curves and lines in (d,e) represent exponential and linear fits to the data, respectively, whereas the dashed lines in (f) are meant to guide the eye.

successively rinsed with ethanol, acetone, and isopropanol and blown dry using $\mathrm{N}_{2}$, followed by annealing in a muffle oven in air at $1000{ }^{\circ} \mathrm{C}$ for $2 \mathrm{~h}$ to create flat terraces separated by atomic steps. ${ }^{40}$ Muscovite mica was cleaved immediately before film deposition using a doubleedge razor blade in order to create a fresh, silica-terminated (001) surface. ${ }^{41}$

Film thicknesses were measured by X-ray reflectivity (Rigaku SmartLab). The film morphology was evaluated by scanning electron microscopy (SEM, Hitachi S-4800) and atomic force microscopy (AFM, Veeco Multimode V). Tapping-mode AFM imaging was performed in air using silicon probes with a nominal tip radius of less than $10 \mathrm{~nm}$ (Bruker). Cross-sectional bright-field transmission electron microscopy (TEM) images were recorded using a $200 \mathrm{kV}$ Tecnai F20 instrument. The TEM samples were prepared with the focused ion beam lift-out method using a FEI Quanta 3D 200i DualBeam instrument.

Crystallinity of the films was studied by X-ray diffraction (XRD, Rigaku SmartLab) in either grazing incidence (GIXRD, incident angle $\left.1^{\circ}\right)$ or $\theta-2 \theta$ diffraction geometry using a $\mathrm{Cu} \mathrm{K} \alpha(\lambda=1.54 \AA) \mathrm{X}$-ray beam. In-plane $2 \theta \chi$ measurements using the same instrument were used to estimate the crystallite size. Micro-Raman spectra were measured in the back-scattering geometry using a confocal Raman microscope (NT-MDT Ntegra) with a $532 \mathrm{~nm}$ laser and a 100X objective. Films grown on $90 \mathrm{~nm} \mathrm{SiO}_{2} / \mathrm{Si}$ substrates were used for the Raman measurements because of the enhanced signal of $2 \mathrm{D}$ materials on such substrates. ${ }^{42}$ Most Raman samples were encapsulated with a $50 \mathrm{~nm} \mathrm{Al} \mathrm{Si}_{y} \mathrm{O}_{z}$ layer to minimize laser damage. The protective layer enabled the use of the full laser power of $5 \mathrm{~mW}$, whereas bare films were damaged when more than a hundredth of this power was used.

Grain size of the films was estimated using multiple methods. Using plan-view SEM and cross-sectional TEM, tens of representative grains were identified from the images. The grain size was then calculated as average \pm standard deviation. The peak broadening in the in-plane $\mathrm{XRD}$ measurements was used to determine the crystallite size using Scherrer's equation. This gives an estimate of the in-plane crystallite size contrary to the conventional out-of-plane measurements, where the crystallite size is determined perpendicular to the film plane and is therefore limited by the film thickness.

Optical transmission measurements were performed on films deposited on transparent SLG and sapphire substrates using a Hitachi
U-2000 UV-vis spectrophotometer. Band gaps were estimated using Tauc plots constructed from the transmittance measurements of 1000 cycle films on sapphire.

Film composition was analyzed by time-of-flight elastic recoil detection analysis (ToF-ERDA) using a $50 \mathrm{MeV}^{79} \mathrm{Br}^{7+}$ ion beam. The incident angle with respect to the sample surface was $16^{\circ}$, and the scattering angle was $40^{\circ}$. The film surface and film/substrate interface regions were excluded from the analysis. Energy-dispersive X-ray spectroscopy (EDS, Oxford INCA 350 connected to the Hitachi S4800 SEM) was used for semiquantitative analysis of film composition.

Photodetector structures were made by evaporating gold electrodes through source-drain shadow masks (Ossila E421, channel length 30 $\mu \mathrm{m}$ and width $1 \mathrm{~mm}$ ). $\mathrm{A} \mathrm{ZrS}_{2}$ or $\mathrm{HfS}_{2}$ film was then deposited on top of the $\mathrm{Au} / \mathrm{SLG}$ substrate at $400{ }^{\circ} \mathrm{C}$ using 1000 cycles. A protective $\mathrm{Al}_{x} \mathrm{Si}_{y} \mathrm{O}_{z}$ layer was immediately deposited using 100 cycles at $400{ }^{\circ} \mathrm{C}$ as described above. The Au contact pads were contacted by scratching the $\mathrm{Al}_{x} \mathrm{Si}_{y} \mathrm{O}_{z} / \mathrm{MS}_{2} / \mathrm{Au} / \mathrm{SLG}$ stacks, and the resulting scratch was filled by conductive silver cement thinned by acetone (EM-Tec AG42, Micro to Nano). The Ag cement was allowed to cure for $24 \mathrm{~h}$ in a desiccator prior to soldering electrical connections.

Electrical measurements were performed using a Keithley 2450 SourceMeter instrument. Solid-state laser diodes (CPS-series, Thorlabs) emitting 405, 450, 532, 635, 780, and $980 \mathrm{~nm}$ light with $\mathrm{mm}$-scale beams, that is, larger than the device area, were used to illuminate the devices through the protective $\mathrm{Al}_{x} \mathrm{Si}_{y} \mathrm{O}_{z}$ layer. The incident power density was adjusted using absorptive neutral density filters (NE-series, Thorlabs) and calculated using the specifications of the lasers and the filters. Unless otherwise noted, the responsivity was calculated using photocurrent measured after $60 \mathrm{~s}$ of illumination. Response times were determined using pulsed light (laser turned on/ off). Because of the presence of a slow component in the photoresponse and the resulting slow decay (minutes to even hours) back to the dark current, care was taken to start the measurements with small power densities to avoid the influence of previous measurements.

\section{RESULTS AND DISCUSSION}

In this work, we deposited crystalline, 2D films of $\mathrm{HfS}_{2}$ and $\mathrm{ZrS}_{2}$ on different substrates by ALD using $\mathrm{MCl}_{4}(\mathrm{M}=\mathrm{Hf}, \mathrm{Zr})$ 
and $\mathrm{H}_{2} \mathrm{~S}$ as the precursors (Figure 1a). $\mathrm{HfS}_{2}$ and $\mathrm{ZrS}_{2}$ are 2D semiconductors that crystallize in a layered, $1 \mathrm{~T}$ type crystal structure with octahedral coordination of sulfur atoms around the metal atoms (Figure 1b,c). In the crystal structure, each socalled monolayer (a sulfur-metal-sulfur trilayer) is separated from the next monolayer by a van der Waals gap. Monolayer thickness, in other words, the distance between two metal layers, is $0.58 \mathrm{~nm}$ in both $\mathrm{HfS}_{2}$ and $\mathrm{ZrS}_{2}$. We prepared continuous films with the thickness controlled in the range of a few monolayers to $10 \mathrm{~nm}$ and beyond on substrates up to $5 \times$ $5 \mathrm{~cm}^{2}$ in size. The substrate size was limited only by the size of our research-scale equipment, and upscaling the process is possible using larger ALD reactors.

Development of an ALD process begins with identification of possible precursors and their evaluation for the film growth. Herein, we chose simple halides, $\mathrm{HfCl}_{4}$ and $\mathrm{ZrCl}_{4}$, that are commonly used to deposit the respective oxides by ALD both in research and industry. Gaseous $\mathrm{H}_{2} \mathrm{~S}$ was selected as the sulfur precursor. Thermodynamically, the reactions between $\mathrm{MCl}_{4}$ and $\mathrm{H}_{2} \mathrm{~S}$ (eq 1) are favorable with $\Delta G$ values of $-75 \mathrm{~kJ} /$ $\mathrm{mol}(\mathrm{M}=\mathrm{Zr})$ and $-68 \mathrm{~kJ} / \mathrm{mol}(\mathrm{M}=\mathrm{Hf})$ at $500{ }^{\circ} \mathrm{C}$ and approximately $10 \mathrm{~kJ} / \mathrm{mol}$ less negative at $300{ }^{\circ} \mathrm{C}$.

For comparison, the $\Delta G$ values for growth of the oxides (eq 2) are more negative, -160 and $-162 \mathrm{~kJ} / \mathrm{mol}$ for $\mathrm{Zr}$ and $\mathrm{Hf}$ at $500{ }^{\circ} \mathrm{C}$.

$$
\begin{aligned}
& \mathrm{MCl}_{4}(\mathrm{~g})+2 \mathrm{H}_{2} \mathrm{~S}(\mathrm{~g}) \rightarrow \mathrm{MS}_{2}+4 \mathrm{HCl}(\mathrm{g}) \\
& \mathrm{MCl}_{4}(\mathrm{~g})+2 \mathrm{H}_{2} \mathrm{O}(\mathrm{g}) \rightarrow \mathrm{MO}_{2}+4 \mathrm{HCl}(\mathrm{g})
\end{aligned}
$$

We also deposited $\mathrm{HfS}_{2}$ films using $\mathrm{HfI}_{4}$ and $\mathrm{H}_{2} \mathrm{~S}$ (Figure S5), which suggests that other halides excluding the practically involatile fluorides may also be used. The film deposition becomes more thermodynamically favorable when going from chlorides to iodides such that $\Delta G$ is $-110 \mathrm{~kJ} / \mathrm{mol}$ for the $\mathrm{HfI}_{4}$ $+\mathrm{H}_{2} \mathrm{~S}$ reaction at $500{ }^{\circ} \mathrm{C}$ compared to $-68 \mathrm{~kJ} / \mathrm{mol}$ for $\mathrm{HfCl}_{4}+$ $\mathrm{H}_{2} \mathrm{~S}$.

Commonly used alkylamide precursors, $\mathrm{M}(\mathrm{NEtMe})_{4}$, were also tested, but the films deposited with $\mathrm{H}_{2} \mathrm{~S}$ were nonuniform and significantly more unstable in air than the films deposited using $\mathrm{MCl}_{4}$ (Section S2 in the Supporting Information).

We found it crucial to minimize the presence of impurities such as $\mathrm{H}_{2} \mathrm{O}$ and $\mathrm{O}_{2}$ in the precursors (using high-purity metal precursors and $\mathrm{H}_{2} \mathrm{~S}$ purifier), carrier gas (using $\mathrm{N}_{2}$ purifier) as well as on the walls of the reactor (by preannealing or preevacuation of the reactor) to prevent oxidation of the $\mathrm{HfS}_{2}$ and $\mathrm{ZrS}_{2}$ films during their deposition (Section $\mathrm{S} 1$ in the Supporting Information). Thermodynamic calculations show that oxidation of $\mathrm{HfS}_{2}$ and $\mathrm{ZrS}_{2}$ is favorable by $\mathrm{H}_{2} \mathrm{O}(\Delta G \approx$ $-100 \mathrm{~kJ} / \mathrm{mol}$, eq 3$)$ and even more favorable by $\mathrm{O}_{2}(\Delta G \approx$ $-400 \mathrm{~kJ} / \mathrm{mol}$, eq 4) both at room temperature and under the deposition conditions.

$$
\begin{aligned}
& \mathrm{MS}_{2}+2 \mathrm{H}_{2} \mathrm{O}(\mathrm{g}) \rightarrow \mathrm{MO}_{2}+2 \mathrm{H}_{2} \mathrm{~S}(\mathrm{~g}) \\
& \mathrm{MS}_{2}+\mathrm{O}_{2}(\mathrm{~g}) \rightarrow \mathrm{MO}_{2}+\mathrm{S}_{2}(\mathrm{~g})
\end{aligned}
$$

In the film growth experiments, saturation of the growth rate, a signature of the saturative surface reactions of ALD, was observed when at least $0.5 \mathrm{~s}$ pulses of $\mathrm{MCl}_{4}$ and $\mathrm{H}_{2} \mathrm{~S}$ separated by $1.0 \mathrm{~s} \mathrm{~N}_{2}$ purges were used at the optimal deposition temperature of $400{ }^{\circ} \mathrm{C}$ (Figures $1 \mathrm{~d}$ and S9). The growth rates were approximately 0.11 and $0.08 \AA$ /cycle for $\mathrm{HfS}_{2}$ and $\mathrm{ZrS}_{2}$. These growth rates imply that, on average, the $5.8 \AA$ thick $\mathrm{MS}_{2}$ monolayer is formed after 50 and 70 ALD cycles for $\mathrm{HfS}_{2}$ and
$\mathrm{ZrS}_{2}$. Linear growth was observed for both materials (Figure 1e). A small difference in the intersects of the fitted line with the $x$-axis was observed $\left(-75 \pm 9\right.$ and $23 \pm 30$ cycles for $\mathrm{HfS}_{2}$ and $\mathrm{ZrS}_{2}$, respectively). This may be because of differences in the nucleation behavior, although no signs of island growth were observed for either material even when examining films deposited using as few as 50 cycles. Differences in the oxidation behavior of the two materials may also affect the results, as the thickness measurements were performed ex situ after a brief exposure to the atmosphere.

The highest growth rates for both of the materials were found at $400{ }^{\circ} \mathrm{C}$ (Figure 1f). The decrease of the growth rates at lower temperatures is attributed to insufficient reactivity of the precursors, whereas at higher temperatures, changes in the densities of reactive surface groups may explain the decreasing growth rates. Additionally, as discussed below in detail, the film composition and crystallinity changed as a function of the deposition temperature, which is also likely to affect the growth rate. Crystalline $\mathrm{MS}_{2}$ films were obtained at $350-450{ }^{\circ} \mathrm{C}$, and the main emphasis here is at films deposited at $400{ }^{\circ} \mathrm{C}$. At lower temperatures, amorphous films were obtained, which oxidized either in the reactor or rapidly in the atmosphere and contained chlorine residues as verified by EDS. Oxidation of the films deposited at $450{ }^{\circ} \mathrm{C}$ and above was observed to take place during deposition, despite the measures taken to exclude oxidants from the reactor.

In most deposition temperatures, the growth rate of $\mathrm{HfS}_{2}$ was somewhat higher than that of $\mathrm{ZrS}_{2}$. This may be due to differences in the reactivity and adsorption density of the $\mathrm{MCl}_{4}$ precursors. It is also possible that the growth rates were affected by the different preconditioning treatment used for $\mathrm{HfS}_{2}$ and $\mathrm{ZrS}_{2}$ (see the Experimental Section). The observed growth rates are relatively low compared to the oxide films grown from the same metal precursors with $\mathrm{H}_{2} \mathrm{O}$, that is, approximately $0.5 \AA /$ cycle at $500{ }^{\circ} \mathrm{C}$ in the same reactor. ${ }^{43,44}$ The difference is attributed to the inert surface of $2 \mathrm{D}$ materials, which results in a limited number of reactive sites that are present mostly at the edges of grains and defects.

In terms of the growth behavior, both of the processes behaved in a fairly similar manner, as is expected due to the analogous precursors, the identical crystal structures, and the similar properties of $\mathrm{HfS}_{2}$ and $\mathrm{ZrS}_{2}$ stemming from the chemical similarity of $\mathrm{Hf}$ and $\mathrm{Zr}$. The two processes produced continuous films completely covering the $5 \times 5 \mathrm{~cm}^{2}$ substrates, although there was some thickness gradient in the films in the direction of the gas flow (Figure S10). The thickness gradients were in the opposite directions so that the $\mathrm{HfS}_{2}$ films were thickest near the precursor inlet and the $\mathrm{ZrS}_{2}$ films were thickest near the outlet. Such thickness gradients arise from inlet effects and readsorption of byproducts, ${ }^{45}$ for example, and are often observed in films deposited in the cross-flow-type reactors like the one used in this work, including $\mathrm{HfO}_{2}$ and $\mathrm{ZrO}_{2}$ grown from the chlorides and $\mathrm{H}_{2} \mathrm{O} .{ }^{43,44}$ The uniformity can often be improved by simply placing the substrates further downstream from the point where the film growth starts or by using an ALD reactor of a different design, for example, of shower-head type.

The crystallinity (Figure 2a) and morphology (Figure S11) of the $\mathrm{ZrS}_{2}$ films deposited on silicon at different temperatures were examined by GIXRD and SEM. The films deposited at the lowest temperatures of $\leq 300{ }^{\circ} \mathrm{C}$ were smooth and amorphous. Crystallization of $\mathrm{ZrS}_{2}$ in the $1 \mathrm{~T}$ phase (Powder Diffraction File (PDF) 011-0679) was observed at a deposition 

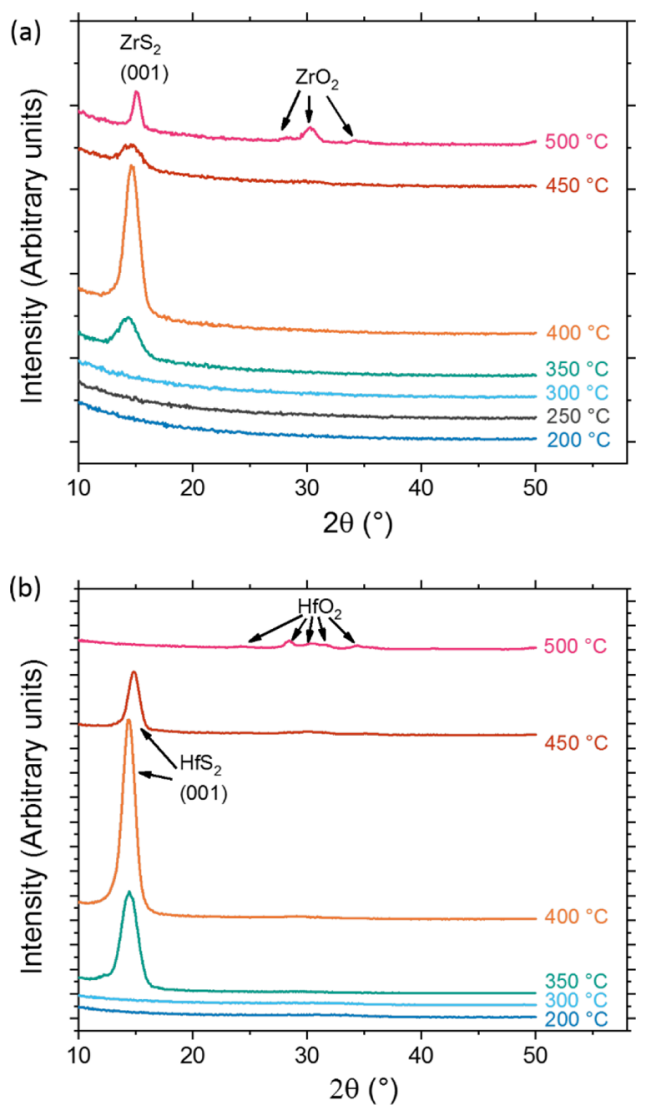

Figure 2. GIXRD diffractograms of (a) $\mathrm{ZrS}_{2}$ and (b) $\mathrm{HfS}_{2}$ films deposited at different temperatures using 1000 cycles. The diffractograms have been offset vertically for clarity.

temperature of $350{ }^{\circ} \mathrm{C}$, and crystalline $\mathrm{ZrS}_{2}$ was seen in the films deposited at up to $500{ }^{\circ} \mathrm{C}$, although some $\mathrm{ZrO}_{2}$ (monoclinic, PDF 007-0343) was also observed in the film deposited at 450 and $500{ }^{\circ} \mathrm{C}$ (see also diffractograms in logarithmic scale in Figure S12). The oxidation is the most obvious at high temperatures because the oxidation reactions (eqs 3 and 4) become faster at higher temperatures. The $\mathrm{ZrS}_{2}$ films appeared relatively smooth, although they also exhibited some scattered flakes on the surface. The presence of flakes is relatively common for ALD-grown $2 \mathrm{D}$ materials, and in many cases, a much more flaky morphology is observed, as has been the case for $\mathrm{MoS}_{2},{ }^{46,47} \mathrm{PbI}_{2}{ }^{48}$ and $\mathrm{ReS}_{2}$ (ref 49) films. The grain size of the $\mathrm{ZrS}_{2}$ films was estimated to range from tens to a few tens of nanometers. For example, for a 1000 cycle $\mathrm{ZrS}_{2}$ film deposited at $400{ }^{\circ} \mathrm{C}$ ( $8 \mathrm{~nm}$ thick), the grain size was estimated as $17 \pm 7$ and $14 \pm 4 \mathrm{~nm}$ using plan-view SEM and cross-sectional TEM, respectively. In-plane XRD measurements gave an average crystallite size of $23 \mathrm{~nm}$.

The density of the $\mathrm{ZrS}_{2}$ films deposited at temperatures around $400{ }^{\circ} \mathrm{C}$ was close to or slightly above the $\mathrm{ZrS}_{2}$ bulk density of $3.87 \mathrm{~g} / \mathrm{cm}^{3}$, which is in line with the dense structure and good crystallinity of the films (Figure S14a).

The $\mathrm{HfS}_{2}$ films deposited at $300{ }^{\circ} \mathrm{C}$ and below were also smooth (Figure S13) and X-ray amorphous (Figure 2b). The film deposited at 350 to $400{ }^{\circ} \mathrm{C}$ consisted of crystalline $\mathrm{HfS}_{2}$ (1T phase, PDF 028-0444) and had smooth surfaces without any visible flakes, although small crystallites from approximately ten to a few tens of $\mathrm{nm}$ in diameter were seen on the surface. The films deposited at $450{ }^{\circ} \mathrm{C}$ and above exhibited increased surface roughness and signs of oxidation as evidenced by the appearance of GIXRD reflections attributed to $\mathrm{HfO}_{2}$ (monoclinic, PDF 034-0104). The density of the films followed the changes in the composition from $\mathrm{HfS}_{2}$ (bulk density $6.03 \mathrm{~g} / \mathrm{cm}^{3}$ ) to $\mathrm{HfO}_{2}$ (bulk density $9.68 \mathrm{~g} / \mathrm{cm}^{3}$ ). ${ }^{50}$ The densities of the films deposited at $350-400{ }^{\circ} \mathrm{C}$ were close to the bulk density of $\mathrm{HfS}_{2}$, whereas both the amorphous films deposited at $200-300{ }^{\circ} \mathrm{C}$ (approximately $7.5-8 \mathrm{~g} / \mathrm{cm}^{3}$ ) and the film deposited at $500{ }^{\circ} \mathrm{C}$ (approximately $9 \mathrm{~g} / \mathrm{cm}^{3}$ ) had higher densities because of oxidation of the films (Figure S14b).

We believe that oxidation at the highest deposition temperatures arises from the presence of residual oxidants, most probably $\mathrm{H}_{2} \mathrm{O}$ or $\mathrm{O}_{2}$, in the ALD reactor. Further decrease of the impurity levels and the use of a reactor capable of higher temperatures should enable the deposition of $\mathrm{HfS}_{2}$ and $\mathrm{ZrS}_{2}$ films also at higher temperatures with the potential to improve the crystallinity and grain size, as $\mathrm{HfCl}_{4}$ and $\mathrm{ZrCl}_{4}$ are

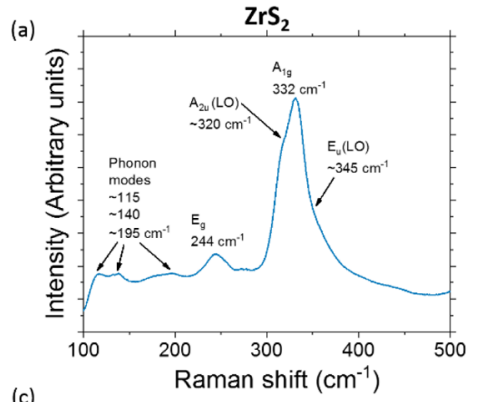

(c)

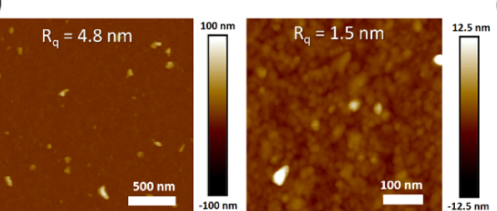

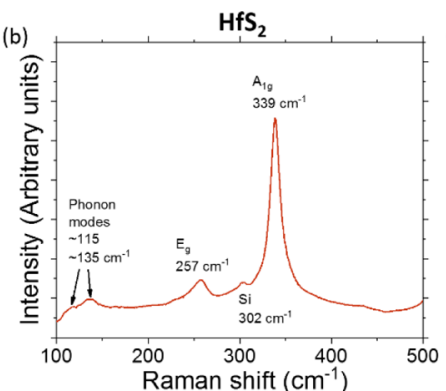
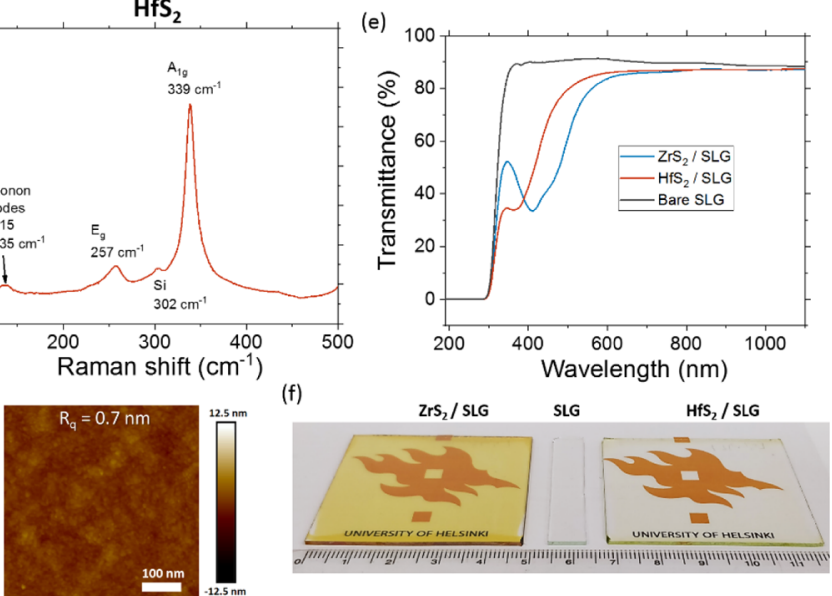

Figure 3. Raman spectra of (a) $\mathrm{ZrS}_{2}$ and (b) $\mathrm{HfS}_{2}$ films on $90 \mathrm{~nm} \mathrm{SiO} / \mathrm{Si}$ substrates. AFM images and roughness values $\left(R_{\mathrm{q}}\right)$ of $(\mathrm{c}) \mathrm{ZrS}_{2}(2 \times 2$ $\mu \mathrm{m}^{2}$ and $500 \times 500 \mathrm{~nm}^{2}$ areas $)$ and (d) $\mathrm{HfS}_{2}\left(500 \times 500 \mathrm{~nm}^{2}\right.$ area) films on silicon. (e) UV-vis transmittance spectra and (f) photographs of $\mathrm{ZrS}_{2}$ and $\mathrm{HfS}_{2}$ films deposited on $5 \times 5 \mathrm{~cm}^{2}$ SLG substrates along with a bare substrate. The films were deposited at $400{ }^{\circ} \mathrm{C}$ using $1000 \mathrm{cycles}$, resulting in thicknesses of approximately $8\left(\mathrm{ZrS}_{2}\right)$ or $10 \mathrm{~nm}\left(\mathrm{HfS}_{2}\right)$. The films used for the Raman measurements were protected using an $\mathrm{Al}_{x} \mathrm{Si}_{y} \mathrm{O}_{z}$ layer as explained in the text. 
known to have excellent thermal stability. Indeed, the $\mathrm{HfCl}_{4}+$ $\mathrm{H}_{2} \mathrm{O}$ process has been shown to exhibit saturative growth at temperatures as high as $940{ }^{\circ} \mathrm{C} . .^{51}$

The films deposited using $\mathrm{Hfl}_{4}$ and $\mathrm{H}_{2} \mathrm{~S}$ were found to be crystalline at temperatures as low as $300{ }^{\circ} \mathrm{C}$, that is, $50{ }^{\circ} \mathrm{C}$ lower compared to $\mathrm{HfCl}_{4}$. Use of other hafnium and zirconium precursors might thus enable deposition of crystalline films at lower temperatures. The use of $\mathrm{HfI}_{4}$ instead of $\mathrm{HfCl}_{4}$ seemed to increase the film roughness, however (Figure S5).

Next, the films deposited from the chlorides at $400{ }^{\circ} \mathrm{C}$ were characterized in more detail. The Raman spectrum of the $\mathrm{ZrS}_{2}$ film was dominated by a rather broad, asymmetric peak centered at $332 \mathrm{~cm}^{-1}$ (Figure 3a). Roubi and Carlone $\mathrm{C}^{52}$ explained the broadness and shape of this peak by the presence of longitudinal optical modes $\mathrm{A}_{2 \mathrm{u}}(\mathrm{LO})$ and $\mathrm{E}_{\mathrm{u}}(\mathrm{LO})$ at approximately 320 and $345 \mathrm{~cm}^{-1}$ in addition to the out-ofplane $A_{1 g}$ mode at $332 \mathrm{~cm}^{-1}$. Alternatively, Mañas-Valero et al. $^{35}$ speculated that the broadening of the $A_{1 g}$ mode could be due to anharmonic effects. A weaker in-plane $\mathrm{E}_{\mathrm{g}}$ mode was observed at $244 \mathrm{~cm}^{-1}$ along with weak phonon modes at approximately 115,140 , and $195 \mathrm{~cm}^{-1}$. The frequency of the $\mathrm{A}_{1 \mathrm{~g}}$ mode is in agreement with reports on bulk ${ }^{35,51}$ and fewlayer ${ }^{35} \mathrm{ZrS}_{2}$, whereas the $\mathrm{E}_{\mathrm{g}}$ frequency is somewhat lower compared to the reported values of $249-251 \mathrm{~cm}^{-1} \cdot{ }^{35,50}$ Full width at half-maxima ( $f w h m$ ) of the $E_{g}$ and $A_{1 g}$ modes were approximately 21 and $18 \mathrm{~cm}^{-1}$, which, although large, are comparable to bulk $\mathrm{ZrS}_{2}$. ${ }^{35}$

The Raman spectrum of $\mathrm{HfS}_{2}$ also revealed the $\mathrm{A}_{1 \mathrm{~g}}$ (339 $\left.\mathrm{cm}^{-1}\right)$ and $\mathrm{E}_{\mathrm{g}}\left(257 \mathrm{~cm}^{-1}\right)$ modes along with phonon modes at approximately 115 and $135 \mathrm{~cm}^{-1}$ in agreement with literature (Figure $3 \mathrm{~b}) .^{53}$ The $\mathrm{A}_{1 \mathrm{~g}}$ mode was much narrower compared to $\mathrm{ZrS}_{2}$ with an fwhm of $9.5 \mathrm{~cm}^{-1}$. Furthermore, the broadening of the $A_{1 g}$ mode was symmetrical with no obvious signs of optical modes, although Cingolani et al. ${ }^{53}$ have reported a weak $\mathrm{E}_{\mathrm{u}}(\mathrm{LO})$ mode at $321 \mathrm{~cm}^{-1}$ in bulk $\mathrm{HfS}_{2}$.

AFM was used to study the surface roughness and morphology of the films. As indicated by SEM, there were some flakes on the surface of the $\mathrm{ZrS}_{2}$ films deposited at 400 ${ }^{\circ} \mathrm{C}$. Some of the flakes were up to $50 \mathrm{~nm}$ high in case of an approximately $8 \mathrm{~nm}$ thick film deposited using 1000 cycles (Figure 3c). Accordingly, the root-mean-square $\left(R_{\mathrm{q}}\right)$ roughness was rather high at $4.8 \mathrm{~nm}$ in a $2 \times 2 \mu \mathrm{m}^{2}$ area. However, in a $500 \times 500 \mathrm{~nm}^{2}$ area without larger flakes, the surface was relatively smooth with a roughness of $1.5 \mathrm{~nm}$. The roughness of a 1000 -cycle $\mathrm{HfS}_{2}$ film deposited at $400{ }^{\circ} \mathrm{C}$ was only $0.7 \mathrm{~nm}$, and no flakes were seen on the $\mathrm{HfS}_{2}$ surface. The presence of $\mathrm{ZrS}_{2}$ flakes raising high above the film surface can be understood by considering the much higher reactivity and therefore higher growth rate on the flake edges compared to the relatively inert basal planes of $2 \mathrm{D}$ materials. Thus, after a flake starts to grow at an angle with respect to the substrate, it can rapidly grow to stand high above the rest of the film. ${ }^{47,48}$ In the present case, relatively few flakes were observed on $\mathrm{ZrS}_{2}$ and none on $\mathrm{HfS}_{2}$, which may reflect a difference in the density of defects or their reactivity or differences in stress between the $\mathrm{HfS}_{2}$ and $\mathrm{ZrS}_{2}$ films.

$\theta-2 \theta$ and GI XRD showed that both of the materials exhibited some, although quite weak preferred (001) orientation as evidenced by the lack of other reflections besides (00l) and a (001) rocking curve fwhm of approximately $5^{\circ}$ (Figures S15 and S16). The preferred (001) orientation and relatively smooth surface were retained in even approximately $100 \mathrm{~nm}$ thick films deposited using 10 000 cycles (Figure S17).

Optical transmission measurements were performed on films deposited on transparent SLG and sapphire substrates. Films of both materials exhibited high transmittance from $1100 \mathrm{~nm}$ down to about $600 \mathrm{~nm}$ (Figure 3e). At shorter wavelengths, the $\mathrm{ZrS}_{2}$ film absorbed more strongly than the $\mathrm{HfS}_{2}$ film despite the somewhat lower thickness (growth rate) of $\mathrm{ZrS}_{2}$, which is in line with the reported smaller bulk band gap of $\mathrm{ZrS}_{2}$. The strong absorption below approximately $350 \mathrm{~nm}$ is due to the SLG substrate and could be circumvented using sapphire substrates (Figure S18). The films deposited on sapphire using 1000 cycles were estimated to have indirect band gaps of $1.87\left(\mathrm{HfS}_{2}\right)$ and $1.82 \mathrm{eV}\left(\mathrm{ZrS}_{2}\right)$ as shown in Figure S19. The Tauc plots suggested also the presence of direct band gaps of $2.86\left(\mathrm{HfS}_{2}\right)$ and $2.41 \mathrm{eV}\left(\mathrm{ZrS}_{2}\right)$. The values for both indirect and direct band gaps are in good agreement with literature for bulk $\mathrm{HfS}_{2}$ and $\mathrm{ZrS}_{2}$ (Table S1). The larger band gaps of $\mathrm{HfS}_{2}$ compared to $\mathrm{ZrS}_{2}$ are also obvious in the visual appearance of the films, as the $\mathrm{HfS}_{2}$ films were pale yellow in color while the $\mathrm{ZrS}_{2}$ films appeared darker yellow or slightly orange (Figure $3 \mathrm{f}$ ).

Elemental composition of the films was analyzed by ToFERDA (Table 1). For the analysis, thick films were deposited

Table 1. Elemental Composition of $\mathrm{HfS}_{2}$ and $\mathrm{ZrS}_{2}$ Films as Analyzed by ToF-ERDA ${ }^{a}$

$\begin{array}{lcc}\text { element } & \text { concentration in } \mathrm{HfS}_{2} \text { (at. \%) } & \text { concentration in } \mathrm{ZrS}_{2} \text { (at. \%) } \\ \mathrm{Hf} & 31.75 \pm 0.18 & <0.15 \\ \mathrm{Zr} & <0.15 & 32.59 \pm 0.77 \\ \mathrm{~S} & 61.23 \pm 1.01 & 63.72 \pm 1.46 \\ \mathrm{~S} / \mathrm{M} \text { ratio } & 1.93 \pm 0.03 & 1.96 \pm 0.06 \\ \mathrm{O} & 6.12 \pm 0.32 & 3.35 \pm 0.25 \\ \mathrm{Cl} & <0.2 & <0.2 \\ \mathrm{C} & 0.08 \pm 0.04 & 0.11 \pm 0.06 \\ \mathrm{~N} & 0.09 \pm 0.05 & 0.03 \pm 0.02 \\ \mathrm{H} & 0.57 \pm 0.34 & 0.12 \pm 0.10 \\ \mathrm{Na} & 0.16 \pm 0.05 & 0.09 \pm 0.09\end{array}$

${ }^{a}$ The films were grown at $400{ }^{\circ} \mathrm{C}$ using 10000 cycles, and the surface and the film/substrate interface were excluded from the analysis.

using 10000 cycles to minimize the effects of native $\mathrm{SiO}_{2}$ layer and atmospheric contamination as well as surface oxidation. Both of the materials were close to stoichiometric and pure with low impurity levels, the main impurity being oxygen, about $3.4\left(\mathrm{ZrS}_{2}\right)$ or 6.1 at. \% $\left(\mathrm{HfS}_{2}\right)$. Remarkably, the chlorine content was below the detection limit of 0.2 at. \%. The low $(<1$ at. \%) levels of $\mathrm{C}, \mathrm{N}, \mathrm{H}$, and $\mathrm{Na}$ were attributed to contamination from the atmosphere, as out of these elements only hydrogen is present in the precursors. As expected, the film surface contained elevated levels of oxygen (Figure S20), which is attributed to the surface oxidation of the films, whereas the oxygen in the bulk of the films may be due to residual $\mathrm{O}_{2}$ or $\mathrm{H}_{2} \mathrm{O}$ present in the ALD reactor during the deposition or the postdeposition oxidation proceeding through grain boundaries (the films were exposed to air briefly prior to analysis). The somewhat higher oxygen concentration in $\mathrm{HfS}_{2}$ compared to $\mathrm{ZrS}_{2}$ may reflect larger tendency of oxidation for $\mathrm{HfS}_{2}$.

Thinner $\mathrm{HfS}_{2}$ and $\mathrm{ZrS}_{2}$ films were deposited by decreasing the number of deposition cycles. However, the crystallinity of the films seemed to rapidly deteriorate when less than 500 
cycles were applied, which corresponds to thicknesses below approximately 4-5 nm (Figures S21 and S22). We attributed this to the oxidation of the films either in the atmosphere, although they were stored in dried air (desiccator) between measurements or in the ALD reactor while cooling down the reactor after deposition. Thus, we decided to deposit a protective layer on top of the $\mathrm{HfS}_{2} / \mathrm{ZrS}_{2}$ films at $400{ }^{\circ} \mathrm{C}$ immediately following the film deposition. Because of the ease of oxidation of the sulfides, especially at elevated temperatures, oxygen- and water-free ALD processes were preferred. Using the water-free ALD oxide chemistry with two metal precursors, a metal alkoxide $\left(\mathrm{Si}\left(\mathrm{O}^{n} \mathrm{Bu}\right)_{4}\right)$, and a metal chloride $\left(\mathrm{AlCl}_{3}\right)$ with no additional reactants, an $\mathrm{Al}_{x} \mathrm{Si}_{y} \mathrm{O}_{z}$ layer was deposited at $400{ }^{\circ} \mathrm{C} .{ }^{39}$ The deposition required neither vacuum breaking nor changing the deposition temperature and added less than $10 \mathrm{~min}$ to the process flow (Figure 4a). Using the standard $\mathrm{AlCl}_{3}+\mathrm{H}_{2} \mathrm{O}$ process at $400{ }^{\circ} \mathrm{C}$ instead resulted in partial oxidation of the $\mathrm{ZrS}_{2}$ and $\mathrm{HfS}_{2}$ films, as did only pulsing $\mathrm{H}_{2} \mathrm{O}$ over the $\mathrm{MS}_{2}$ films (Figure S23).
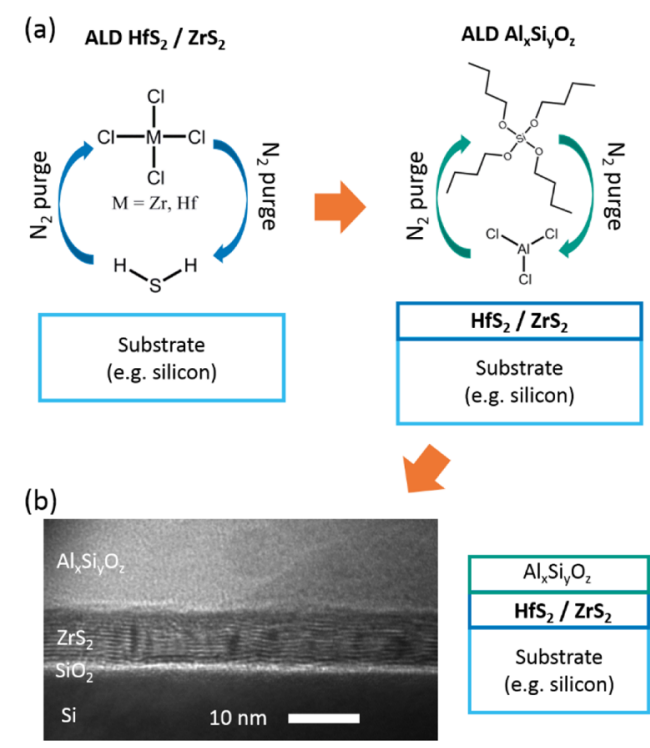

(c)

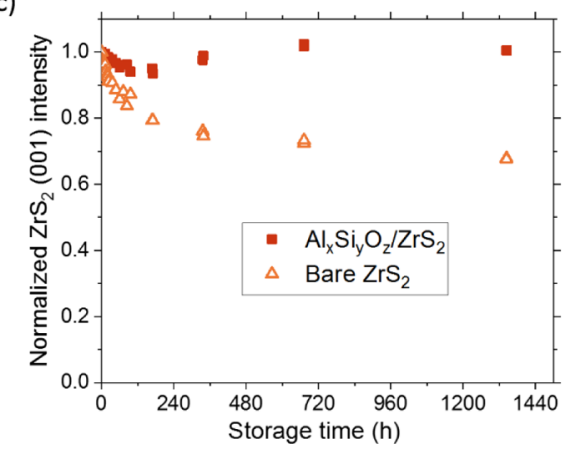

Figure 4. (a) Schematic of the deposition of $\mathrm{HfS}_{2}$ or $\mathrm{ZrS}_{2}$ and the protective $\mathrm{Al}_{x} \mathrm{Si}_{y} \mathrm{O}_{z}$ layers by $\mathrm{ALD}$ at $400{ }^{\circ} \mathrm{C}$. (b) Cross-sectional TEM micrograph of an $\mathrm{Al}_{x} \mathrm{Si}_{y} \mathrm{O}_{z}$-encapsulated $\mathrm{ZrS}_{2}$ film on a $\mathrm{Si}$ substrate with a native oxide layer. (c) Normalized intensity of the (001) X-ray reflection of $\mathrm{ZrS}_{2}\left(14.6^{\circ} 2 \theta\right)$ as a function of storage time in ambient conditions for bare and $\mathrm{Al}_{x} \mathrm{Si}_{y} \mathrm{O}_{z}$-encapsulated $\mathrm{ZrS}_{2}$ films. The $\mathrm{ZrS}_{2}$ and $\mathrm{Al}_{x} \mathrm{Si}_{y} \mathrm{O}_{z}$ films were deposited at $400{ }^{\circ} \mathrm{C}$ using 1000 and 100 cycles, resulting in thicknesses of approximately 8 and $50 \mathrm{~nm}$, respectively.
TEM showed that a dense, well-crystallized $\mathrm{ZrS}_{2}$ layer was protected by an amorphous $50 \mathrm{~nm}$ thick $\mathrm{Al}_{x} \mathrm{Si}_{y} \mathrm{O}_{z}$ layer (Figure $4 \mathrm{~b}$ ). Although the TEM image indicates that there may be a thin interfacial layer between the $\mathrm{ZrS}_{2}$ and $\mathrm{Al}_{x} \mathrm{Si}_{y} \mathrm{O}_{z}$ layers, the observation that even very thin $\mathrm{ZrS}_{2}$ films remained crystalline under the protective layer (to be discussed later) proves the gentle and nonoxidizing nature of the $\mathrm{Al}_{x} \mathrm{Si}_{y} \mathrm{O}_{z}$ deposition. An encapsulated, approximately $8 \mathrm{~nm}$ thick $\mathrm{ZrS}_{2}$ film showed no detectable oxidation during 2 months of storage in air, while the intensity of the (001) X-ray reflection of a bare $\mathrm{ZrS}_{2}$ film decreased by more than $30 \%$ (Figure $4 \mathrm{c}$ ). We note that such a dielectric protective layer could, perhaps at a smaller thickness, be used either as an interfacial layer or even the main dielectric layer for various semiconductor devices, such as FETs. Furthermore, the $\mathrm{Al}_{x} \mathrm{Si}_{y} \mathrm{O}_{z}$ layer with a rather low permittivity may be replaced with, for example, ( $\mathrm{Hf} / \mathrm{Zr})_{x} \mathrm{Si}_{y} \mathrm{O}_{z}$ grown using similar ALD chemistry. ${ }^{54}$

The crystallinity of the thinner $\mathrm{ZrS}_{2}$ films deposited using less than 500 cycles was found to clearly improve when the protective $\mathrm{Al}_{x} \mathrm{Si}_{y} \mathrm{O}_{z}$ layer was added to the deposition scheme (Figure S24). This suggests that without the protective layer the films were partially oxidized either in the reactor after deposition or in air before or during the measurements. Raman spectroscopy revealed that even a film deposited with 100 cycles, nominally only about $0.6 \mathrm{~nm}$ or one monolayer thick, was crystalline $\mathrm{ZrS}_{2}$ (Figure 5). The intensities of the Raman

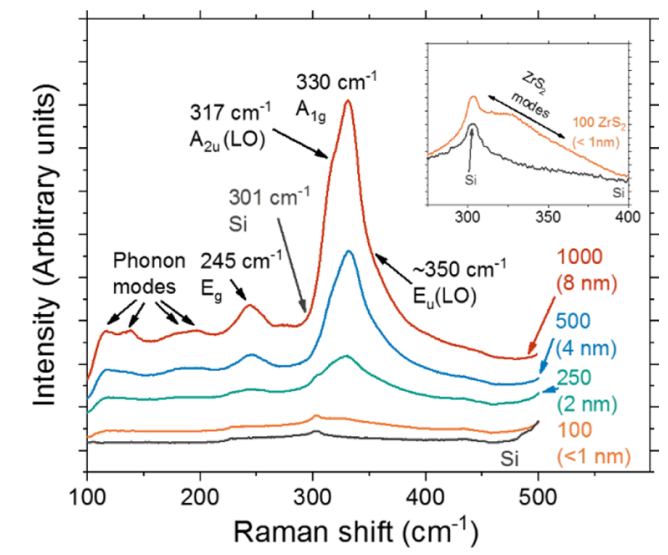

Figure 5. Raman spectra of $\mathrm{ZrS}_{2}$ films deposited using a different number of ALD cycles (thicknesses in parentheses). The inset shows the substrate and the 100 cycle film in more detail. The films were deposited on silicon substrates with a $90 \mathrm{~nm} \mathrm{SiO}_{2}$ layer at $400{ }^{\circ} \mathrm{C}$ followed by deposition of a protective $\mathrm{Al}_{x} \mathrm{Si}_{y} \mathrm{O}_{z}$ layer. The spectra have been offset vertically for clarity.

signals attributed to $\mathrm{ZrS}_{2}$ expectedly increased with increasing thickness (number of ALD cycles). No changes in the frequencies of the $\mathrm{ZrS}_{2}$ Raman modes were observed as a function of film thickness. This is in agreement with the Raman studies of $\mathrm{ZrS}_{2}$ by Mañas-Valero et al. ${ }^{35}$ but in contrast to the group 6 TMDCs such as $\mathrm{MoS}_{2}$ and $\mathrm{WS}_{2}{ }^{55}$

Different applications require TMDC films to be deposited on different substrates. Therefore, we deposited $\mathrm{ZrS}_{2}$ films on various substrates, including the commonly used oxide substrates $\left(\mathrm{SiO}_{2}\right.$, sapphire, SLG, and mica) and ALD-grown films of different material groups $\left(\mathrm{Al}_{2} \mathrm{O}_{3}, \mathrm{TiO}_{2}\right.$, Ir, and $\left.\mathrm{ZnS}\right)$. Crystalline $\mathrm{ZrS}_{2}$ films were successfully deposited on all of the substrates (Figure 6), although there were differences in the growth rates (Table S2) and the preferred orientation (Figures 


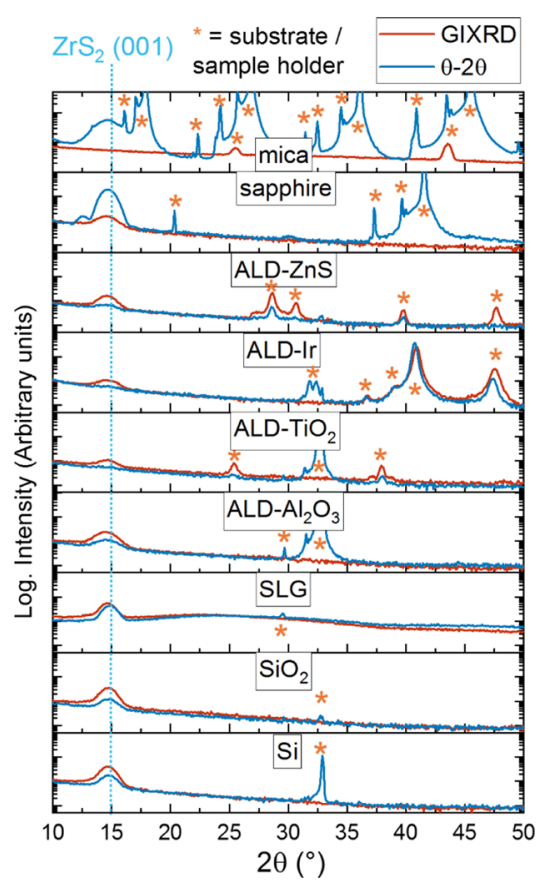

Figure 6. Grazing incidence (red) and $\theta-2 \theta$ (blue) X-ray diffractograms of $\mathrm{ZrS}_{2}$ films deposited on different substrates at 400 ${ }^{\circ} \mathrm{C}$ using 1000 cycles. The $\mathrm{ZrS}_{2}$ (001) reflection is marked with a cyan dashed line. All the other reflections, including the two GIXRD peaks on mica, arise from the substrates or the sample holder and are marked with orange asterisks.

6 and S25) of the films. Most strongly (001) oriented films were deposited on mica, followed by sapphire, SLG, and Si with either a native or thermal $\mathrm{SiO}_{2}$ layer. The preferred (001) orientation was particularly strong for the films grown on mica, as is evident from the lack of the (001) peak in the GIXRD measurements (Figure 6) and the narrow (001) rocking curve fwhm of $0.16^{\circ}$ (Figure S25b).

Using SEM, the $\mathrm{ZrS}_{2}$ films deposited on the SLG and silicon substrates were found to contain the highest density of flakes on the surface (Figure S26). The films grown on mica and sapphire were very smooth as confirmed by their surface roughnesses being less than $1.0 \mathrm{~nm}$. The ALD-grown $\mathrm{Ir}, \mathrm{TiO}_{2}$, and $\mathrm{ZnS}$ films were relatively rough by themselves, but no major changes in their morphology were seen after the deposition of $\mathrm{ZrS}_{2}$. The differences in the growth rates and especially in the morphology and preferred orientation highlight the importance of the choice of the substrate in the growth of $2 \mathrm{D}$ materials and motivate further studies on the subject.

Finally, to prove the semiconductor quality and applicability of the deposited films, we constructed photodetector (photoresistor) devices by evaporating patterned $\mathrm{Au}$ electrodes on glass substrates through a shadow mask followed by deposition of $\mathrm{HfS}_{2}(\sim 10 \mathrm{~nm})$ or $\mathrm{ZrS}_{2}(\sim 8 \mathrm{~nm})$ and protective $\mathrm{Al}_{x} \mathrm{Si}_{y} \mathrm{O}_{z}$ $(\sim 50 \mathrm{~nm})$ layers by ALD (Figure 7a,b). The $30 \mu \mathrm{m} \times 1 \mathrm{~mm}$ devices were illuminated through the transparent $\mathrm{Al}_{x} \mathrm{Si}_{y} \mathrm{O}_{z}$ layer using laser sources with different wavelengths. The photodetectors were operated in photoresistor-mode using a modest bias of $1 \mathrm{~V}$ between the electrodes unless otherwise noted.

Upon illumination by $405 \mathrm{~nm}$ light, the conductivity (current) of both of the materials increased because of photogenerated charge carriers that were then separated by the electric field between the electrodes, as is shown by the current-voltage measurements (logarithmic scale in Figure $7 \mathrm{c}, \mathrm{d}$ and linear scale in Figures S27 and S28). As expected for a photoresistor, no photoresponse in the absence of an external bias was observed. Whereas with the $\mathrm{ZrS}_{2}$ device, the current increased rather linearly with increasing bias voltage both in dark and under illumination, and with the $\mathrm{HfS}_{2}$ device, the current increased more slowly at lower bias voltages, followed by a faster increase at larger biases. This suggests (nearly) ohmic contacts for $\mathrm{ZrS}_{2} / \mathrm{Au}$ in contrast to a Schottky junction for $\mathrm{HfS}_{2} / \mathrm{Au}$. Indeed, it is known that many metal/TMDC pairs often form Schottky junctions. ${ }^{56}$ The current flowing through the $\mathrm{HfS}_{2}$ device was one to two orders of magnitude lower compared to $\mathrm{ZrS}_{2}$ both in dark and under illumination, which likely reflects the higher electrical conductivity of $\mathrm{ZrS}_{2}$, although the effect of contacts must also be kept in mind.

Both the $\mathrm{HfS}_{2}$ and $\mathrm{ZrS}_{2}$ devices exhibited relatively fast photoresponse under pulsed $405 \mathrm{~nm}$ illumination (Figure 7e). Thanks to the protective $\mathrm{Al}_{x} \mathrm{Si}_{y} \mathrm{O}_{z}$ layer, the photodetectors showed no decline in performance when stored in air for at least a week or when operated for several hours. Under a $1 \mathrm{~V}$ bias and a $22 \mathrm{~mW} / \mathrm{cm}^{2}$ incident power density, the photoresponsivity of the $\mathrm{ZrS}_{2}$ device was calculated to be 50 $\mathrm{mA} / \mathrm{W}$, and the rise and decay times were 35 and $230 \mathrm{~ms}$ (Figure S29). Under identical conditions, the responsivity of the $\mathrm{HfS}_{2}$ device was much lower, approximately $0.18 \mathrm{~mA} / \mathrm{W}$, with estimated rise and decay times of $<100$ and $300 \mathrm{~ms}$ (Figure S30). The photoresponsivity $(R)$ was calculated using eq 5 , where $I_{\text {photo }}$ is the photocurrent, in other words, the current under illumination $\left(I_{\text {light }}\right)$ minus the dark current $\left(I_{\text {dark }}\right) . P_{\text {light }}$ is the incident power, in other words, the power density of the light source (Pd) times the area of the device $(A)$. The rise (decay) time was defined as the time to reach $90 \%(10 \%)$ of the photocurrent when the laser was turned on (off).

$$
R=\frac{I_{\text {photo }}}{P_{\text {light }}}=\frac{I_{\text {light }}-I_{\text {dark }}}{\mathrm{Pd} \cdot A}
$$

The photoresponse behavior of both of the materials consisted of fast and slow components that originate from different processes. A two-phase exponential function was required to fit the photoresponse of the $\mathrm{ZrS}_{2}$ device presented in Figure 7e, which suggests the presence of two processes with approximately an order of magnitude difference in time constants, that is, $5 / 28$ and $16 / 230 \mathrm{~ms}$ for the current rise and decay, respectively (Figure S29). A third component of even slower processes contributes to the slow decay of the current back to the dark current level on the time scale of minutes (Figures S31-S33). The slow response and high responsivity typical of $2 \mathrm{D}$ photodetectors are often attributed to the photogating effect, where photogenerated electrons (holes) are trapped near the conduction (valence) band. Physically, the trapped charge carriers mostly end up at the film/substrate interface, which results in an additional electric field perpendicular to the film that regulates the conductance along the film similar to an external gate. ${ }^{57}$ As demonstrated by Thakar et al., ${ }^{58}$ the effect of photogating may be reduced using an external gate voltage, which results in shorter response times at the expense of decreased responsivity.

The photocurrent increased with increasing power density in a sublinear fashion as is commonly observed for $2 \mathrm{D}$ photodetectors. The behavior could be described by a power law $I_{\text {photo }} \alpha P^{x}$, where the exponent $x$ was determined to be 
(a)

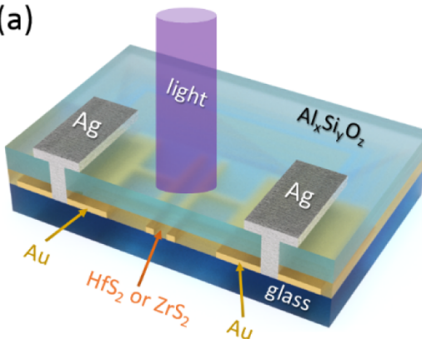

(b)

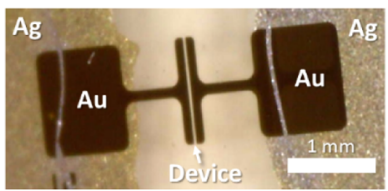

(f)

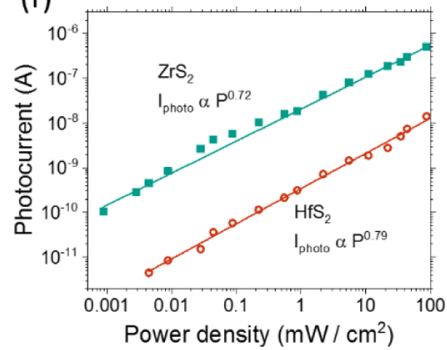

(c)

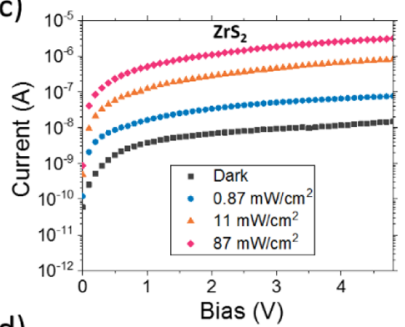

(d)

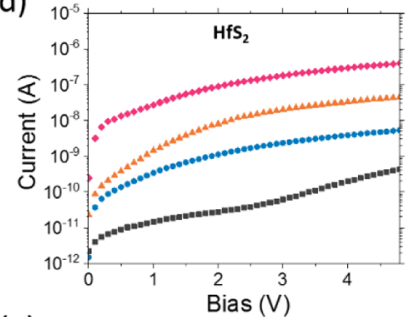

(g)

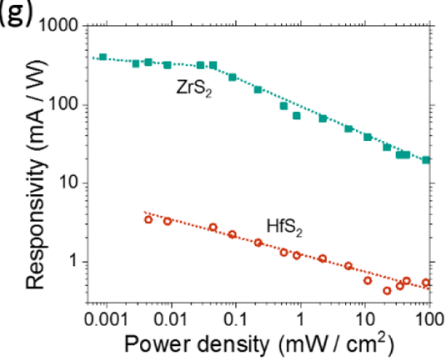

(e)

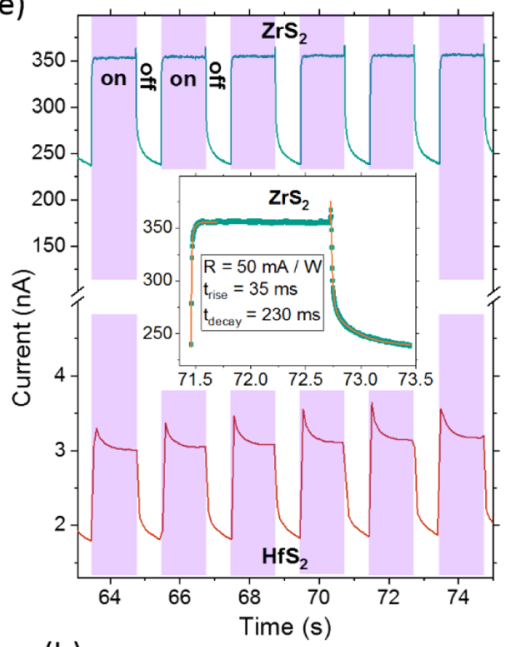

(h)

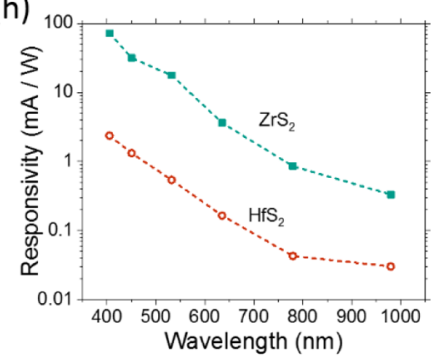

Figure 7. (a) Schematic structure and (b) photograph (taken from the side of the glass substrate) of the $\mathrm{Al}_{x} \mathrm{Si}_{y} \mathrm{O}_{z} / \mathrm{ZrS}_{2} / \mathrm{glass}$ photodetector structure with $\mathrm{Au}$ electrodes. $\mathrm{I}-V$ curves of (c) $\mathrm{ZrS}_{2}$ and (d) $\mathrm{HfS}_{2}$ photodetectors in dark and under illumination with a $405 \mathrm{~nm}$ laser using different power densities. (e) Time-dependent response (I-t) of $\mathrm{HfS}_{2}$ and $\mathrm{ZrS}_{2}$ photodetectors under pulsed illumination with a $405 \mathrm{~nm}$ laser at a power density of $22 \mathrm{~mW} / \mathrm{cm}^{2}$. The inset shows one on-off cycle for $\mathrm{ZrS}_{2}$ in more detail along with the extracted responsivity as well as rise and decay times. The lines in the inset are two-phase exponential functions fitted to the data. (f) Photocurrent as a function of illumination power density under $405 \mathrm{~nm}$ illumination. The lines represent power law curves fitted into the data. $(\mathrm{g})$ Responsivity as a function of illumination power density under $405 \mathrm{~nm}$ illumination. The dashed lines are meant to guide the eye. (h) Responsivity as a function of illumination wavelength under a power density of approximately $1 \mathrm{~mW} / \mathrm{cm}^{2}$. The dashed lines are meant to guide the eye.

0.79 and 0.72 for $\mathrm{HfS}_{2}$ and $\mathrm{ZrS}_{2}$ (Figure 7f), respectively. Therefore, the highest responsivity values were achieved at the lowest power densities (Figure $7 \mathrm{~g}$ ) such that the responsivity reached $3.4 \mathrm{~mA} / \mathrm{W}$ for $\mathrm{HfS}_{2}\left(0.0044 \mathrm{~mW} / \mathrm{cm}^{2}\right)$ and $500 \mathrm{~mA}$ / $\mathrm{W}$ for $\mathrm{ZrS}_{2}\left(0.00087 \mathrm{~mW} / \mathrm{cm}^{2}\right)$. Interestingly, at the lowest power densities $\left(\leq 0.044 \mathrm{~mW} / \mathrm{cm}^{2}\right)$, only a weak dependence between power density and responsivity was seen for $\mathrm{ZrS}_{2}$. The sublinear behavior at larger power densities has been attributed to defects and charged impurities either in the $2 \mathrm{D}$ film or at the interfaces. ${ }^{19,57}$ Trap states with a long lifetime, which are likely present as evidenced by the slow photoresponse component, can also contribute to the sublinear behavior. The response times were longer at smaller power densities, which also support the presence of trap states with a long lifetime.

The relatively low bias voltage of $1 \mathrm{~V}$ was chosen to minimize the dark current and consequently power consumption of the photodetectors, although higher bias voltages obviously increase the responsivity at the cost of increased dark current. Using $5 \mathrm{~V}$ bias and a low power density of $0.087 \mathrm{~mW} /$ $\mathrm{cm}^{2}$, a responsivity of $1.25 \mathrm{~A} / \mathrm{W}$ was achieved for $\mathrm{ZrS}_{2}$ (Figure S34).

The spectral response of the $\mathrm{HfS}_{2}$ and $\mathrm{ZrS}_{2}$ photodetectors was tested using lasers of different wavelengths from 405 to $980 \mathrm{~nm}$ (logarithmic scale in Figure $7 \mathrm{~h}$ and linear scale in Figure S35). The results show promise for broadband photodetection: a measurable, although quite small photocurrent was clearly detected even at the infrared wavelengths of
780 and $980 \mathrm{~nm}$. The responsivity rapidly increased toward smaller wavelengths for both of the materials such that the largest responsivity was reached under $405 \mathrm{~nm}$ illumination. As described above, the indirect band gaps of the $\mathrm{HfS}_{2}$ and $\mathrm{ZrS}_{2}$ films were measured to be $1.87 \mathrm{eV}(660 \mathrm{~nm})$ and $1.82 \mathrm{eV}(680$ $\mathrm{nm}$ ). The small but measurable photoresponse at wavelengths above the band gap can be explained by the presence of defect states within the band gap.

The performance of our $\mathrm{HfS}_{2}$ and $\mathrm{ZrS}_{2}$ photodetectors is comparable to the previous reports using few-layer flakes or films grown by CVD at high temperatures. Responsivities of $2.8 \mathrm{~mA} / \mathrm{W}$ (ref 19) and $26.5 \mathrm{~mA} / \mathrm{W}$ (ref 22) for 420 and 450 $\mathrm{nm}$ light, respectively, have been reported using $\mathrm{HfS}_{2}$ flakes grown by CVD at temperatures above $900{ }^{\circ} \mathrm{C}$. For continuous $\mathrm{HfS}_{2}$ films grown at $1000{ }^{\circ} \mathrm{C}$, a much more modest responsivity of $0.01 \mathrm{~mA} / \mathrm{W}$ for $450 \mathrm{~nm}$ light was reported, although the device showed ultrafast response with rise and decay times of 130 and $155 \mu \mathrm{s}$, respectively. ${ }^{21}$ Zheng et al. ${ }^{20}$ reported photodetectors made of a film consisting of vertically oriented $\mathrm{HfS}_{2}$ flakes with a responsivity of less than $0.001 \mathrm{~mA}$ / $\mathrm{W}$ (estimated from the reported data) for $405 \mathrm{~nm}$ light. Using a photo-FET device with an exfoliated $\mathrm{HfS}_{2}$ channel, Xu et al. ${ }^{9}$ reported a large responsivity of $890 \mathrm{~A} / \mathrm{W}$ for $473 \mathrm{~nm}$ light at a gate voltage of $80 \mathrm{~V}$ (channel in on-state), whereas the responsivity was two orders of magnitude lower at zero gate voltage (off-state). There appears to be only one report on a $2 \mathrm{D} \mathrm{ZrS}_{2}$ photodetector: the CVD-grown monolayer flake 
device exhibited responsivity of up to $2.86 \mathrm{~A} / \mathrm{W}$ for $450 \mathrm{~nm}$ light (ref 10). Photodetectors based on other 2D semiconductors such as $\mathrm{MoS}_{2}, \mathrm{MoSe}_{2}$, and $\mathrm{WS}_{2}$ also often exhibit quite similar performance, although there is large variation in results as is discussed in detail in several reviews, and much higher responsivities and shorter response times are also reported in some studies. ${ }^{59-61}$

\section{CONCLUSIONS}

We introduced a scalable method to deposit continuous, largearea films of 2D semiconductors $\mathrm{HfS}_{2}$ and $\mathrm{ZrS}_{2}$ with an accurately controlled thickness ranging from a few monolayers to tens of nanometers. We developed, for the first time, ALD processes for $\mathrm{HfS}_{2}$ and $\mathrm{ZrS}_{2}$ using simple, affordable, thermally stable, and industrially used precursors, $\mathrm{HfCl}_{4}$ and $\mathrm{ZrCl}_{4}$, with $\mathrm{H}_{2} \mathrm{~S}$ as the sulfur source. The processes operate at temperatures compatible with semiconducting processing (around $400{ }^{\circ} \mathrm{C}$ ) and can deposit crystalline films on a variety of substrates. Challenges related to the oxidation of the films during deposition and exposure to air were overcome by minimizing impurities in the reactor and encapsulation with an $\mathrm{Al}_{x} \mathrm{Si}_{y} \mathrm{O}_{z}$ layer grown by $\mathrm{ALD}$ without a vacuum break. The deposited films were highly crystalline, mostly smooth, and of high purity excluding an oxygen content of a few at. \%. The optoelectronic quality of the $\mathrm{HfS}_{2}$ and $\mathrm{ZrS}_{2}$ films was shown by using them as photodetectors, which exhibited performance comparable to $\mathrm{HfS}_{2}$ and $\mathrm{ZrS}_{2}$ films or even single flakes grown at high temperatures. We hope that these first ALD processes for $\mathrm{HfS}_{2}$ and $\mathrm{ZrS}_{2}$ will enable further studies into the use of the materials for various applications, including comparison with the more commonly studied 2D semiconductors such as $\mathrm{MoS}_{2}$, $\mathrm{WS}_{2}$, and $\mathrm{WSe}_{2}$.

\section{ASSOCIATED CONTENT}

\section{S Supporting Information}

The Supporting Information is available free of charge on the ACS Publications website at DOI: 10.1021/acs.chemmater.9b01688.

Discussion on the importance of impurity levels in the reactor, including the use of $\mathrm{H}_{2} \mathrm{~S}$ and $\mathrm{N}_{2}$ gas purifiers and reactor preconditioning, evaluation of alternative $\mathrm{Hf}$ and $\mathrm{Zr}$ precursors, further details on the growth of $\mathrm{HfS}_{2}$ and $\mathrm{ZrS}_{2}$ films and film uniformity, further characterization of the $\mathrm{HfS}_{2}$ and $\mathrm{ZrS}_{2}$ films including density, crystallinity, morphology, optical properties, and elemental depth profiles, comparison of the crystallinity of thin $\mathrm{HfS}_{2}$ and $\mathrm{ZrS}_{2}$ films with and without a protective layer and comparison of different protective layers, thickness, crystallinity, and morphology of $\mathrm{ZrS}_{2}$ films grown on different substrates, additional measurements and graphs of the $\mathrm{HfS}_{2}$ and $\mathrm{ZrS}_{2}$ photodetectors including linear $I-V$ curves, data used to extract responsivity and response times, and examples of photodetector response to both single and repeated pulses of light (PDF)

\section{AUTHOR INFORMATION}

\section{Corresponding Authors}

*E-mail: miika.mattinen@helsinki.fi (M.M.).

*E-mail: mikko.ritala@helsinki.fi (M.R.).

ORCID

Miika Mattinen: 0000-0003-4837-1823
Georgi Popov: 0000-0003-1233-8327

Markku Leskelä: 0000-0001-5830-2800

Mikko Ritala: 0000-0002-6210-2980

\section{Present Address}

${ }^{\S}$ Picosun Oy, Masalantie 365, FI-02430, Masala, Finland.

\section{Author Contributions}

The manuscript was written through contributions of all the authors.

\section{Notes}

The authors declare no competing financial interest.

\section{ACKNOWLEDGMENTS}

The research was supported by ASM Microchemistry and the Finnish Centre of Excellence in ALD (ALDCoE) funded by the Academy of Finland. The authors thank the Electron Microscopy Unit of the Institute of Biotechnology, University of Helsinki, for TEM instrument access.

\section{REFERENCES}

(1) Novoselov, K. S.; Geim, A. K.; Morozov, S. V.; Jiang, D.; Zhang, Y.; Dubonos, S. V.; Grigorieva, I. V.; Firsov, A. A. Electric Field Effect in Atomically Thin Carbon Films. Science 2004, 306, 666-669.

(2) Allen, M. J.; Tung, V. C.; Kaner, R. B. Honeycomb Carbon: A Review of Graphene. Chem. Rev. 2010, 110, 132-145.

(3) Samadi, M.; Sarikhani, N.; Zirak, M.; Zhang, H.; Zhang, H.-L.; Moshfegh, A. Z. Group 6 Transition Metal Dichalcogenide Nanomaterials: Synthesis, Applications and Future Perspectives. Nanoscale Horiz. 2018, 3, 90-204.

(4) Yan, C.; Gong, C.; Wangyang, P.; Chu, J.; Hu, K.; Li, C.; Wang, X.; Du, X.; Zhai, T.; Li, Y.; Xiong, J. 2D Group IVB Transition Metal Dichalcogenides. Adv. Funct. Mater. 2018, 28, 1803305.

(5) Abdulsalam, M.; Joubert, D. P. Optical Spectrum and Excitons in Bulk and Monolayer $\mathrm{MX}_{2}(\mathrm{M}=\mathrm{Zr}, \mathrm{Hf} ; \mathrm{X}=\mathrm{S}$, Se). Phys. Status Solidi B 2016, 253, 705-711.

(6) Jiang, $\mathrm{H}$. Structural and Electronic Properties of $\mathrm{ZrX}_{2}$ and $\mathrm{HfX}_{2}$ $(\mathrm{X}=\mathrm{S}$ and $\mathrm{Se})$ from First Principles Calculations. J. Chem. Phys. 2011, 134, 204705.

(7) Fu, L.; Wang, F.; Wu, B.; Wu, N.; Huang, W.; Wang, H.; Jin, C.; Zhuang, L.; He, J.; Fu, L.; Liu, Y. Van Der Waals Epitaxial Growth of Atomic Layered $\mathrm{HfS}_{2}$ Crystals for Ultrasensitive Near-Infrared Phototransistors. Adv. Mater. 2017, 29, 1700439.

(8) Xu, K.; Huang, Y.; Chen, B.; Xia, Y.; Lei, W.; Wang, Z.; Wang, Q.; Wang, F.; Yin, L.; He, J. Toward High-Performance Top-Gate Ultrathin $\mathrm{HfS}_{2}$ Field-Effect Transistors by Interface Engineering. Small 2016, 12, 3106-3111.

(9) Xu, K.; Wang, Z.; Wang, F.; Huang, Y.; Wang, F.; Yin, L.; Jiang, C.; He, J. Ultrasensitive Phototransistors Based on Few-Layered $\mathrm{HfS}_{2}$. Adv. Mater. 2015, 27, 7881-7887.

(10) Wang, X.; Huang, L.; Jiang, X.-W.; Li, Y.; Wei, Z.; Li, J. Large Scale $\mathrm{ZrS}_{2}$ Atomically Thin Layers. J. Mater. Chem. C 2016, 4, 31433148.

(11) Zhang, M.; Zhu, Y.; Wang, X.; Feng, Q.; Qiao, S.; Wen, W.; Chen, Y.; Cui, M.; Zhang, J.; Cai, C.; Xie, L. Controlled Synthesis of $\mathrm{ZrS}_{2}$ Monolayer and Few-Layers on Hexagonal Boron Nitride. J. Am. Chem. Soc. 2015, 137, 7051-7054.

(12) Kanazawa, T.; Amemiya, T.; Ishikawa, A.; Upadhyaya, V.; Tsuruta, K.; Tanaka, T.; Miyamoto, Y. Few-Layer HfS 2 Transistors. Sci. Rep. 2016, 6, 22277.

(13) Zhang, W.; Huang, Z.; Zhang, W.; Li, Y. Two Dimensional Semiconductors with Possible High Room Temperature Mobility. Nano Res. 2014, 7, 1731.

(14) Singh, D.; Gupta, S. K.; Sonvane, Y.; Kumar, A.; Ahuja, R. 2D$\mathrm{HfS}_{2}$ as an Efficient Photocatalyst for Water Splitting. Catal. Sci. Technol. 2016, 6, 6605-6614. 
(15) Li, S.; Wang, C.; Qiu, H. Single- and Few-Layer $\mathrm{ZrS}_{2}$ as Efficient Photocatalysts for Hydrogen Production under Visible Light. Int. J. Hydrogen Energy 2015, 40, 15503-15509.

(16) Toh, R. J.; Sofer, Z.; Pumera, M. Catalytic Properties of Group 4 Transition Metal Dichalcogenides $\left(\mathrm{MX}_{2} ; \mathrm{M}=\mathrm{Ti}, \mathrm{Zr}, \mathrm{Hf} ; \mathrm{X}=\mathrm{S}\right.$, Se, Te). J. Mater. Chem. A 2016, 4, 18322-18334.

(17) Wen, Y.; Zhu, Y.; Zhang, S. Low Temperature Synthesis of $\mathrm{ZrS}_{2}$ Nanoflakes and Their Catalytic Activity. RSC Adv. 2015, 5, 6608266085 .

(18) Jang, J.-T.; Jeong, S.; Seo, J.-W.; Kim, M.-C.; Sim, E.; Oh, Y.; Nam, S.; Park, B.; Cheon, J. Ultrathin Zirconium Disulfide Nanodiscs. J. Am. Chem. Soc. 2011, 133, 7636-7639.

(19) Yan, C.; Gan, L.; Zhou, X.; Guo, J.; Huang, W.; Huang, J.; Jin, B.; Xiong, J.; Zhai, T.; Li, Y. Space-Confined Chemical Vapor Deposition Synthesis of Ultrathin $\mathrm{HfS}_{2}$ Flakes for Optoelectronic Application. Adv. Funct. Mater. 2017, 27, 1702918.

(20) Zheng, B.; Chen, Y.; Wang, Z.; Qi, F.; Huang, Z.; Hao, X.; Li, P.; Zhang, W.; Li, Y. Vertically Oriented Few-Layered $\mathrm{HfS}_{2}$ Nanosheets: Growth Mechanism and Optical Properties. 2D Mater. 2016, 3, 035024.

(21) Wang, D.; Zhang, X.; Liu, H.; Meng, J.; Xia, J.; Yin, Z.; Wang, Y.; You, J.; Meng, X.-M. Epitaxial Growth of $\mathrm{HfS}_{2}$ on Sapphire by Chemical Vapor Deposition and Application for Photodetectors. 2D Mater 2017, 4, 031012.

(22) Wang, D.; Meng, J.; Zhang, X.; Guo, G.; Yin, Z.; Liu, H.; Cheng, L.; Gao, M.; You, J.; Wang, R. Selective Direct Growth of Atomic Layered $\mathrm{HfS}_{2}$ on Hexagonal Boron Nitride for High Performance Photodetectors. Chem. Mater. 2018, 30, 3819-3826.

(23) Zhu, Y.; Wang, X.; Zhang, M.; Cai, C.; Xie, L. Thickness and Temperature Dependent Electrical Properties of $\mathrm{ZrS}_{2}$ Thin Films Directly Grown on Hexagonal Boron Nitride. Nano Res. 2016, 9, 2931-2937.

(24) Ritala, M.; Niinistö, J. Atomic Layer Deposition. In Chemical Vapour Deposition: Precursors, Processes and Applications; Jones, A. C., Hitchman, M. L., Eds.; Royal Society of Chemistry: Cambridge, 2009; pp 158-206.

(25) Knoops, H. C. M.; Potts, S. E.; Bol, A. A.; Kessels, W. M. M. Atomic Layer Deposition. Handbook of Crystal Growth; Elsevier: Amsterdam, 2015; Vol. 3, pp 1101-1134.

(26) Johnson, R. W.; Hultqvist, A.; Bent, S. F. A Brief Review of Atomic Layer Deposition: From Fundamentals to Applications. Mater. Mater. Today 2014, 17, 236-246.

(27) Ritala, M.; Niinistö, J. Industrial Applications of Atomic Layer Deposition. ECS Trans. 2009, 25 (8), 641-652.

(28) Raaijmakers, I. J. Current and Future Applications of ALD in Micro-Electronics. ECS Trans. 2011, 41 (2), 3-17.

(29) Miikkulainen, V.; Leskelä, M.; Ritala, M.; Puurunen, R. L. Crystallinity of Inorganic Films Grown by Atomic Layer Deposition: Overview and General Trends. J. Appl. Phys. 2013, 113, 021301.

(30) Blanquart, T.; Niinistö, J.; Ritala, M.; Leskelä, M. Atomic Layer Deposition of Groups 4 and 5 Transition Metal Oxide Thin Films: Focus on Heteroleptic Precursors. Chem. Vap. Deposition 2014, 20, 189-208.

(31) Leskelä, M.; Mattinen, M.; Ritala, M. Review Article: Atomic Layer Deposition of Optoelectronic Materials. J. Vac. Sci. Technol., B: Nanotechnol. Microelectron.: Mater., Process., Meas., Phenom. 2019, 37, 030801.

(32) Hao, W.; Marichy, C.; Journet, C. Atomic Layer Deposition of Stable 2D Materials. 2D Mater. 2019, 6, 012001.

(33) Mirabelli, G.; McGeough, C.; Schmidt, M.; McCarthy, E. K.; Monaghan, S.; Povey, I. M.; McCarthy, M.; Gity, F.; Nagle, R.; Hughes, G.; Cafolla, A.; Hurley, P. K.; Duffy, R. Air Sensitivity of $\mathrm{MoS}_{2}, \mathrm{MoSe}_{2}, \mathrm{MoTe}_{2}, \mathrm{HfS}_{2}$, and $\mathrm{HfSe}_{2}$. J. Appl. Phys. 2016, 120, 125102.

(34) Chae, S. H.; Jin, Y.; Kim, T. S.; Chung, D. S.; Na, H.; Nam, H.; Kim, H.; Perello, D. J.; Jeong, H. Y.; Ly, T. H.; Lee, Y. H. Oxidation Effect in Octahedral Hafnium Disulfide Thin Film. ACS Nano 2016, $10,1309-1316$
(35) Mañas-Valero, S.; García-López, V.; Cantarero, A.; Galbiati, M. Raman Spectra of $\mathrm{ZrS}_{2}$ and $\mathrm{ZrSe}_{2}$ from Bulk to Atomically Thin Layers. Appl. Sci. 2016, 6, 264.

(36) Upadhyaya, V.; Kanazawa, T.; Miyamoto, Y. Vacuum Annealing and Passivation of $\mathrm{HfS}_{2}$ FET for Mitigation of Atmospheric Degradation. IEICE Trans. Electron. 2017, E100.C, 453-457.

(37) Kanazawa, T.; Amemiya, T.; Upadhyaya, V.; Ishikawa, A.; Tsuruta, K.; Tanaka, T.; Miyamoto, Y. Performance Improvement of $\mathrm{HfS}_{2}$ Transistors by Atomic Layer Deposition of $\mathrm{HfO}_{2}$. IEEE Trans. Nanotechnol. 2017, 16, 582-587.

(38) Suntola, T. Atomic Layer Epitaxy. Thin Solid Films 1992, 216, 84-89.

(39) Hämäläinen, J.; Ihanus, J.; Sajavaara, T.; Ritala, M.; Leskelä, M. Atomic Layer Deposition and Characterization of Aluminum Silicate Thin Films for Optical Applications. J. Electrochem. Soc. 2011, 158, P15-P21.

(40) Ribič, P. R.; Bratina, G. Behavior of the (0001) Surface of Sapphire upon High-Temperature Annealing. Surf. Sci. 2007, 601, 44-49.

(41) De Poel, W.; Pintea, S.; Drnec, J.; Carla, F.; Felici, R.; Mulder, P.; Elemans, J. A. A. W.; Van Enckevort, W. J. P.; Rowan, A. E.; Vlieg, E. Muscovite Mica: Flatter than a Pancake. Surf. Sci. 2014, 619, 1924

(42) Benameur, M. M.; Radisavljevic, B.; Héron, J. S.; Sahoo, S.; Berger, H.; Kis, A. Visibility of Dichalcogenide Nanolayers. Nanotechnology 2011, 22, 125706.

(43) Ritala, M.; Leskelä, M.; Niinistö, L.; Prohaska, T.; Friedbacher, G.; Grasserbauer, M. Development of Crystallinity and Morphology in Hafnium Dioxide Thin Films Grown by Atomic Layer Epitaxy. Thin Solid Films 1994, 250, 72-80.

(44) Ritala, M.; Leskelä, M. Zirconium Dioxide Thin Films Deposited by ALE Using Zirconium Tetrachloride as Precursor. Appl. Surf. Sci. 1994, 75, 333-340.

(45) Elers, K.-E.; Blomberg, T.; Peussa, M.; Aitchison, B.; Haukka, S.; Marcus, S. Film Uniformity in Atomic Layer Deposition. Chem. Vap. Deposition 2006, 12, 13-24.

(46) Mattinen, M.; Hatanpää, T.; Sarnet, T.; Mizohata, K.; Meinander, K.; King, P. J.; Khriachtchev, L.; Räisänen, J.; Ritala, M.; Leskelä, M. Atomic Layer Deposition of Crystalline $\mathrm{MoS}_{2}$ Thin Films: New Molybdenum Precursor for Low-Temperature Film Growth. Adv. Mater. Interfaces 2017, 4, 1700123.

(47) Sharma, A.; Verheijen, M. A.; Wu, L.; Karwal, S.; Vandalon, V.; Knoops, H. C. M.; Sundaram, R. S.; Hofmann, J. P.; Kessels, W. M. M.; Bol, A. A. Low-Temperature Plasma-Enhanced Atomic layer Deposition of 2-D $\mathrm{MoS}_{2}$ : Large Area, Thickness Control and Tuneable Morphology. Nanoscale 2018, 10, 8615-8627.

(48) Popov, G.; Mattinen, M.; Hatanpää, T.; Vehkamäki, M.; Kemell, M.; Mizohata, K.; Räisänen, J.; Ritala, M.; Leskelä, M. Atomic Layer Deposition of $\mathrm{PbI}_{2}$ Thin Films. Chem. Mater. 2019, 31, 11011109.

(49) Hämäläinen, J.; Mattinen, M.; Mizohata, K.; Meinander, K.; Vehkamäki, M.; Räisänen, J.; Ritala, M.; Leskelä, M. Atomic Layer Deposition of Rhenium Disulfide. Adv. Mater. 2018, 30, 1703622.

(50) CRC Handbook of Chemistry and Physics, 99th ed.; Rumble, J. R., Ed.; CRC Press: Boca Raton, FL, 2018-2019, http://www. hbcpnetbase.com/ (accessed Jan 7, 2019).

(51) Aarik, J.; Aidla, A.; Mändar, H.; Sammelselg, V.; Uustare, T. Texture Development in Nanocrystalline Hafnium Dioxide Thin Films Grown by Atomic Layer Deposition. J. Cryst. Growth 2000, 220, $105-113$.

(52) Roubi, L.; Carlone, C. Resonance Raman Spectrum of $\mathrm{HfS}_{2}$ and $\mathrm{ZrS}_{2}$. Phys. Rev. B: Condens. Matter Mater. Phys. 1988, 37, 6808-6812.

(53) Cingolani, A.; Lugará, M.; Scamarcio, G.; Lévy, F. The Raman Scattering in Hafnium Disulfide. Solid State Commun. 1987, 62, 121123.

(54) Ritala, M.; Kukli, K.; Rahtu, A.; Räisänen, P. I.; Leskelä, M.; Sajavaara, T.; Keinonen, J. Atomic Layer Deposition of Oxide Thin Films with Metal Alkoxides as Oxygen Sources. Science 2000, 288, 319-321. 
(55) Saito, R.; Tatsumi, Y.; Huang, S.; Ling, X.; Dresselhaus, M. S. Raman Spectroscopy of Transition Metal Dichalcogenides. J. Phys.: Condens. Matter 2016, 28, 353002.

(56) Xu, Y.; Cheng, C.; Du, S.; Yang, J.; Yu, B.; Luo, J.; Yin, W.; Li, E.; Dong, S.; Ye, P.; Duan, X. Contacts between Two- and ThreeDimensional Materials: Ohmic, Schottky, and p-n Heterojunctions. ACS Nano 2016, 10, 4895-4919.

(57) Fang, H.; Hu, W. Photogating in Low Dimensional Photodetectors. Adv. Sci. 2017, 4, 1700323.

(58) Thakar, K.; Mukherjee, B.; Grover, S.; Kaushik, N.; Deshmukh, M.; Lodha, S. Multilayer $\mathrm{ReS}_{2}$ Photodetectors with Gate Tunability for High Responsivity and High Speed Applications. ACS Appl. Mater. Interfaces 2018, 10, 36512-36522.

(59) Huo, N.; Konstantatos, G. Recent Progress and Future Prospects of 2D-Based Photodetectors. Adv. Mater. 2018, 30, 1801164.

(60) Xie, C.; Mak, C.; Tao, X.; Yan, F. Photodetectors Based on Two-Dimensional Layered Materials Beyond Graphene. Adv. Funct. Mater. 2017, 27, 1603886.

(61) Wang, F.; Wang, Z.; Yin, L.; Cheng, R.; Wang, J.; Wen, Y.; Shifa, T. A.; Wang, F.; Zhang, Y.; Zhan, X.; He, J. 2D Library beyond Graphene and Transition Metal Dichalcogenides: A Focus on Photodetection. Chem. Soc. Rev. 2018, 47, 6296-6341. 